This item was submitted to Loughborough's Research Repository by the author.

Items in Figshare are protected by copyright, with all rights reserved, unless otherwise indicated.

\title{
Experiences in Barcelona with the use of fibres in segmental linings
}

PLEASE CITE THE PUBLISHED VERSION

https://doi.org/10.1016/j.tust.2011.07.001

\section{PUBLISHER}

(c) Elsevier

\section{VERSION}

AM (Accepted Manuscript)

\section{PUBLISHER STATEMENT}

This work is made available according to the conditions of the Creative Commons Attribution-NonCommercialNoDerivatives 4.0 International (CC BY-NC-ND 4.0) licence. Full details of this licence are available at: https://creativecommons.org/licenses/by-nc-nd/4.0/

\section{LICENCE}

CC BY-NC-ND 4.0

\section{REPOSITORY RECORD}

De la Fuente, Albert, Pablo Pujadas, Ana Blanco, and Antonio Aguado. 2019. "Experiences in Barcelona with the Use of Fibres in Segmental Linings". figshare. https://hdl.handle.net/2134/32314. 


\title{
EXPERIENCES IN BARCELONA WITH THE USE OF FIBERS IN SEGMENTAL LININGS
}

\author{
Albert de la Fuente(1)*, Pablo Pujadas(2), Ana Blanco(3) and Antonio Aguado(4) \\ (1) Civil Engineer. PhD Student and Lecturer. UPC, Barcelona (Spain). \\ (2) Civil Engineer. PhD Student. UPC, Barcelona (Spain). \\ (3) Civil Engineer. PhD Student. UPC, Barcelona (Spain). \\ (4) Civil Engineer. Doctor Professor. UPC, Barcelona (Spain).

\footnotetext{
a Department of Construction Engineering, Universitat Politècnica de Catalunya, UPC, Jordi Girona 1-3, 08034 Barcelona, Spain.

* Corresponding author. Tel.: +34-93-401-0795; fax: +34-93-401-1036; e-mail: albert.de.la.fuente@upc.edu
}

\begin{abstract}
This paper presents the most outstanding experiences regarding the use of fibres as the main reinforcement in precast segmental linings in the metropolitan area of Barcelona. It is known that the addition of structural fibres improves, on the one hand, the mechanical behaviour of the structure during its construction, especially in cases such as the thrust of the jacks, and on the other hand it leads to a reduction of the global costs by reducing the conventional passive reinforcement. The aim of this paper consists in presenting three real experiences that are representative of the application of FRC in urban tunnels and a design methodology to take into account the structural contribution of the fibres. Two particular cases of the application of this design method are presented. In the first case, the use of 25 $\mathrm{kg} / \mathrm{m}^{3}$ of fibers has led to a reduction of $70 \%$ of the conventional reinforcement initially proposed in the project. In the second one, which was planned to employ fibers but without considering its structural contribution, the parametric study reflected the possibility of reducing up to a $38 \%$ of the rebars adding $25 \mathrm{~kg} / \mathrm{m}^{3}$ of steel fibres in the concrete mixture. In light of good results, construction companies in Spain have become aware of the advantages of using fibers in these structures and have carried out experimental stretches. This attitude has also been influenced by the approval of the new Spanish Code, which includes the FRC as a construction material with design purposes.
\end{abstract}

\section{INTRODUCTION}

Fibre reinforced concrete (FRC) is a composite material that has proved to be a competitive material in many types structures (di Prisco and Toniolo, 2000; di Prisco et al., 2009; Walraven 2009, de la Fuente et al., 2010a). In particular, there are many advantages when using FRC in the manufacturing of segmental linings of tunnels built by means of a Tunnel Boring Machine (TBM) (Waal, 1999; Blom, 2002; Plizzari and Tiberti, 2006; Burguers et al., 2007). In this field, the use of steel fibre reinforced concrete (SFRC) improves the mechanical behaviour of concrete enhancing: (1) thoughness; (2) resistence to fire; (3) resistance to fatigue and (4) its response facing impacts and concentrated loads that can be occur in stages prior to the placement of the segments (curing, transport and handling), during its assembling (thrust of the jacks) and during service stage (contact between joints).

Likewise, the use of SFRC may lead to the total or a partial removal of rebars, improving the production efficiency and ensuring economic competitiveness with regards to the traditional solution. There are many studies both experimental (Caratielli et al., 2010) and numerical (Plizzari and Cominoli, 2005; Plizzari and Tiberti 2006; Burguers et al., 2007; Tiberti et al., 2008; Tiberti and Plizzari 2008; Chiaia et al., 2009a; Chiaia et al., 2009b) in which the advantages associated to the use of SFRC in precast segments are proved as well as the use of steel bar reinforced concrete (RC) and SFRC in the same precast concrete segment (RC-SFRC, hereinafter).

In the last 8 years, the construction of more than $120 \mathrm{~km}$ of tunnel has started in the metropolitan area of Barcelona (Spain), some of which are still under construction. The internal diameter $\left(\boldsymbol{D}_{i}\right)$ of these tunnels ranges from $6.00 \mathrm{~m}$ to $10.9 \mathrm{~m}$, with aspect ratios $\left(\lambda=D_{i} / \boldsymbol{h}\right)$ of even 31 as in the Can Zam stretch of the Line 9 Subway of Barcelona. Basically, the applications were either related to railways, metro lines or for hydraulic conduits.

The use of SFRC began at several stretches of Line 9 Subway of Barcelona (started in 2003). Nevertheless, the structural contribution of the fibres was not considered in the design due to the lack of regulations in the Spanish Code regarding the use of FRC. Conversely, they were considered to improve 
the toughness and enhance the cracking control during handling and assembling operations, while rebars kept the main resistant function. In this sense, the most advanced regulations currently available when these first applications were carried out in Barcelona did take already into account the structural contribution of the fibers, but they were too recent (DBV, 1992; RILEM TC 162-TDF, 2003; CNRDT204/2006, 2006). Nowadays, the Spanish regulation CPH (2008) includes SFRC as a material with a structural responsibility.

Subsequently to the beginning of the construction of the Line 9 Subway of Barcelona, several experimental applications of SFRC precast segments were performed in various stretches. In these cases, $60 \mathrm{~kg} / \mathrm{m}^{3}$ of steel fibers were used to replace the steel rebars. However, two groups of stirrups similar to the ones used in the analysis of the Line 1 Subway of Valencia (Venezuela) (Plizzari and Tiberti 2006) were maintained in order to confine the concrete.

Currently, some experiences concerning precast concrete segments reinforced only with fibres have been done (see Table 1), but the great majority of them are related to values of $\lambda$ generally smaller than those used in the Line 9 Subway of Barcelona. Examples of these applications are: a tunnel for the transportation of water in Ecuador (Vandewalle, 2005), Gold Coast and South East Queensland in Australia (Angerer and Chappell, 2008), Heating Tunnel from the Island Amager to Copenhagen in Denmark (Kasper et al., 2008), Line 4 Subway of Sao Paulo (Telles and Figueiredo, 2006), CLEM Jones Tunnel in Brisbane (Rivercity, 2008), Hobson Bay Sewer Tunnel in New Zealand (Maccaferri, 2009) and Bright Water Sewer System Seattle Tacoma in USA (Jones, 2009).

Table 1. International experiences on the use of fibers in tunnels

\begin{tabular}{|c|c|c|c|c|c|}
\hline Project & $\boldsymbol{D}_{\boldsymbol{i}}(\mathrm{m})$ & $\boldsymbol{h}(\mathrm{m})$ & $\boldsymbol{\lambda}$ & $\begin{array}{c}\text { No of } \\
\text { segments }\end{array}$ & Year \\
\hline $\begin{array}{c}\text { Heathrow Baggage Handling } \\
\text { Tunnel (UK) }\end{array}$ & 4.5 & 0.15 & 30.0 & $7+\mathrm{key}$ & 1993 \\
\hline Heathrow Express Tunnel (UK) & 5.7 & 0.22 & 25.8 & $5+\mathrm{key}$ & 1994 \\
\hline $\begin{array}{c}2^{\text {nd }} \text { Heinenoord Tunnel Rotterdam } \\
\text { (ND) }\end{array}$ & 7.6 & 0.35 & 21.7 & $7+\mathrm{key}$ & 1999 \\
\hline Oënzberg (SW) & 11.4 & 0.40 & 28.5 & $7+\mathrm{key}$ & 2003 \\
\hline Channel Tunnel Rail Link (UK) & 7.2 & 0.35 & 20.4 & $9+\mathrm{key}$ & 2004 \\
\hline $\begin{array}{c}\text { Line 9 Subway of Barcelona. Can } \\
\text { Zam stretch (SP) }\end{array}$ & 10.9 & 0.35 & 31.1 & $7+\mathrm{key}$ & 2003 \\
\hline $\begin{array}{c}\text { Heathrow Express Extension to T5 } \\
\text { (UK) }\end{array}$ & 5.7 & 0.22 & 25.8 & $9+\mathrm{key}$ & 2005 \\
\hline $\begin{array}{c}\text { Line 9 Subway of Barcelona. } \\
\text { Stretch I (Spain) }\end{array}$ & 8.4 & 0.32 & 26.3 & $6+\mathrm{key}$ & 2006 \\
\hline San Vicente Tunnel (USA) & 3.6 & 0.18 & 20.3 & $5+\mathrm{key}$ & 2006 \\
\hline $\begin{array}{c}\text { Beacon Hill Station and Tunnels } \\
\text { (USA) }\end{array}$ & 5.7 & 0.30 & 19.1 & $6+\mathrm{key}$ & 2009 \\
\hline $\begin{array}{c}\text { Line 4 of the Underground of Sao } \\
\text { Paulo (BR) }\end{array}$ & 8.4 & 0.35 & 24.1 & $7+\mathrm{key+invert}$ & 2009 \\
\hline Clem Jones Tunnel (AUS) & 11.4 & 0.40 & 28.5 & $8+\mathrm{key}$ & 2010 \\
\hline
\end{tabular}

The challenge in the recent experiences carried out in the metropolitan area of Barcelona was to analyze the feasibility of exceeding the diameters previously reached. Thus, the purpose of this article is, on the one hand, to present these experiences. On the other hand, this article also aims at showing the design methodology used for the optimization of the amount of fibres $\left(C_{f}\right)$ in SFRC and RC-SFRC precast segments.

\section{PIONEER EXPERIENCE IN THE METROPOLITAN AREA OF BARCELONA}

The first pilot test for the application of SFRC in precast segments was carried out in the year 2004, in the Can Zam stretch of the Line 9 Subway. It must be highlighted that the execution and the working conditions in this first experience were highly adverse: descending stretch and water leaks with a temperature of up to $60^{\circ} \mathrm{C}$. The solution adopted in this case was a ring with a $\boldsymbol{D}_{i}=10.9 \mathrm{~m}$, divided by an 
intermediate slab separating two independent levels (one for each traffic direction). The thickness of the segment was $0.35 \mathrm{~m}$, and a FRC with $60 \mathrm{~kg} / \mathrm{m}^{3}$ of steel fibers dosage was used. A total of thirty rings were constructed; three of them were instrumented in order to carry out a loading test for simulating the soil pressure in the field conditions by means of jacks (Molins et al., 2009).

In Fig. 1a the instrumented specimen is presented. Notice, that the conventional reinforcement was limited to the stirrups (a similar solution was developed by Plizzari and Tiberti (2006)). Likewise, Fig. 1b shows the flat-bed press placed in the extrados of the segment to perform the loading test.
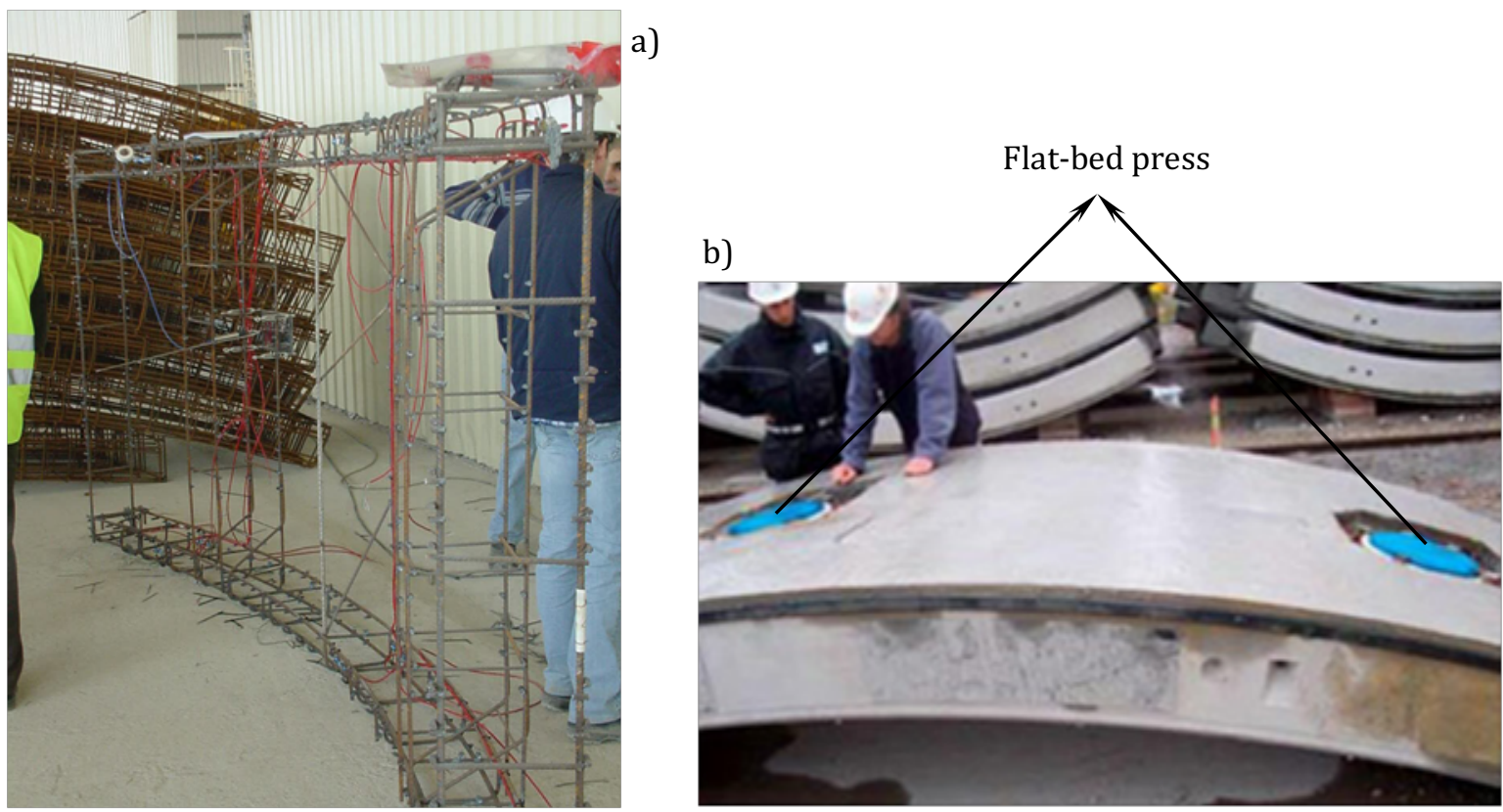

Fig. 1. Load test of the RC-SFRC precast segments: a) instrumented specimen and b) flat-bed press configuration.

As previously mentioned, the working conditions were adverse. As a matter of fact, some splitting cracks and local failures appeared. Fig. 2a shows the crack pattern generated during the assembling of the segments. This cracking was due to the high eccentricity of the load transmitted by the jacks in the descending part of the stretch (Burguers et al., 2007; Cavalaro, 2009). Fig. 2b also shows the existence of water leaks. Nonetheless, there was no concrete detachment thanks to the presence of fibres bridging the cracks.
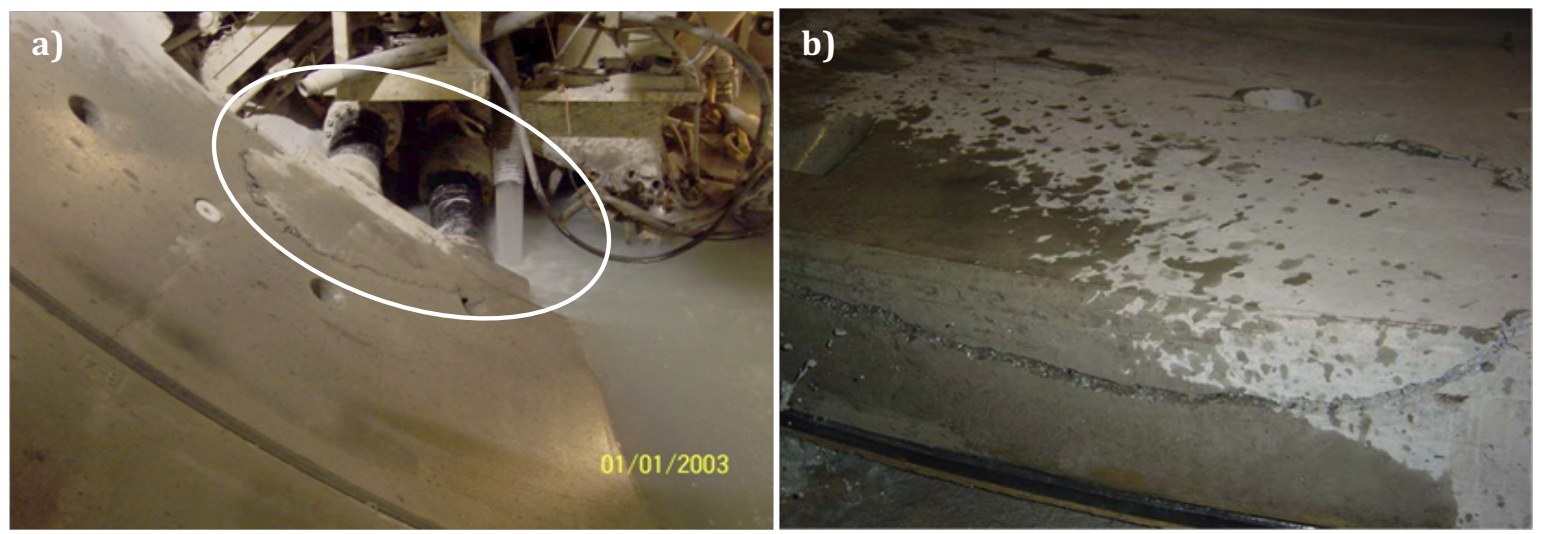

Fig. 1. (a) Assembling operations: (a) crack pattern due to the thrust of the jacks and (b) presence of water leaks.

Even considering the problems already mentioned, which also took place in the stretches with traditional reinforcement, the results from the loading test were satisfactory (Molins et al., 2009). In spite of the success achieved, the solution was not generalized in the whole tunnel for several reasons, many of them bearing no relation to the technical reasons. 
On the basis of the results obtained in this pilot application and the international experiences related with the use of SFRC in precast segments (see Table 1), new ones were proposed in the metropolitan area of Barcelona: FontSanta-Trinitat Tunnel and Terrassa Tunnel. In the first case, 10 optimized RC-SFRC rings were placed, while in the second case a RC-SFRC precast segmental lining was used in the whole tunnel.

\section{NUMERICAL MODEL FOR THE NONLINEAR ANALYSIS OF SECTIONS}

\subsection{Introduction}

The cross sectional behaviour of the precast segments was simulated by means the model called Analysis of Evolutive Sections (AES) presented in (de la Fuente et al., 2008). The structural feasibility of the application of fibers in the studied rings, as well as the optimization of its reinforcement, was dealt with AES. With this aim, the moment-curvature $\left(\boldsymbol{M}_{\boldsymbol{k}^{-}} \chi\right)$ and the interaction $\left(\boldsymbol{N}_{u^{-}} \boldsymbol{M}_{u}\right)$ diagrams were used to provide the necessary information about the mechanical behaviour both in SLS and in ULS for each control cross-section of the segment.

\subsection{Sectional analysis model}

\subsubsection{Modeling of the materials}

The concrete is dicretized in layers with constant thickness, whereas steel rebars are simulated as concentrated-area elements. Subsequently, the suitable constitutive model is assigned to each element in order to integrate the stresses resulting from a given deformation plane $\left(\varepsilon_{0}, \chi\right)$ (see Fig. $3 a$ ).

The addition of steel fibres modifies the behaviour of SFRC depending on the volume of fibers used (Bencardino et al., 2008). Its response under uniaxial compression is described with the expression suggested by Barros and Figueiras, 1999. On the other hand, the simulation of its post-cracking behaviour is solved by means of the model type $\sigma_{c}-\varepsilon_{c}$ suggested in RILEM TC 162-TDF, 2003. This is an internationally accepted model (see Fig. $3 \mathrm{~b}$ ) which has already been used in several numericalexperimental contrasting applications obtaining excellent results (Blanco et al., 2010, de la Fuente et al., 2010b).

The crack width $(w)$ is evaluated differently depending on the type of reinforcement of the section: for RC sections the formulation proposed in (EC-2, 1992) is used, whereas in the case of SFRC-RC sections an extension of the previous formulation (Vandewalle, 2000) is used.

The steel for rebars is simulated with the bilinear diagram presented in Fig. 3c.

\subsubsection{Basic hypotheses}

The following hypotheses have been considered: (1) perfect bond between the materials; (2) sections remain plane before the application of the external forces or after imposing fixed strains and (3) shear strains are negligible, therefore, these were not taken into account.

\subsubsection{Equilibrium and compatibility}

Once the suitable constitutive equations have been assigned to each of the materials, a NewtonRaphson iterative method (Yang et al., 2005) is used to solve the nonlinear equation system resulting from the considering the equilibrium conditions (Eqs. (1) and (2)) and compatibility (Eq. 3).

$$
\begin{aligned}
& N=\int_{A_{c}} \sigma_{c}\left(\varepsilon_{c}\right) \cdot d A_{c}+\sum_{i=1}^{n_{s}} \sigma_{s, i}\left(\varepsilon_{s}\right) \cdot A_{s, i} \\
& M+N y_{c d g}=\int_{A_{c}} \sigma_{c}\left(\varepsilon_{c}\right) \cdot y_{c} \cdot d A_{c}+\sum_{i=1}^{n_{b}} \sigma_{s, i}\left(\varepsilon_{s}\right) \cdot y_{s, i} A_{s, i} \\
& \varepsilon_{c}\left(y_{c}\right)=\varepsilon_{o}+y_{c} \cdot \chi
\end{aligned}
$$


a)

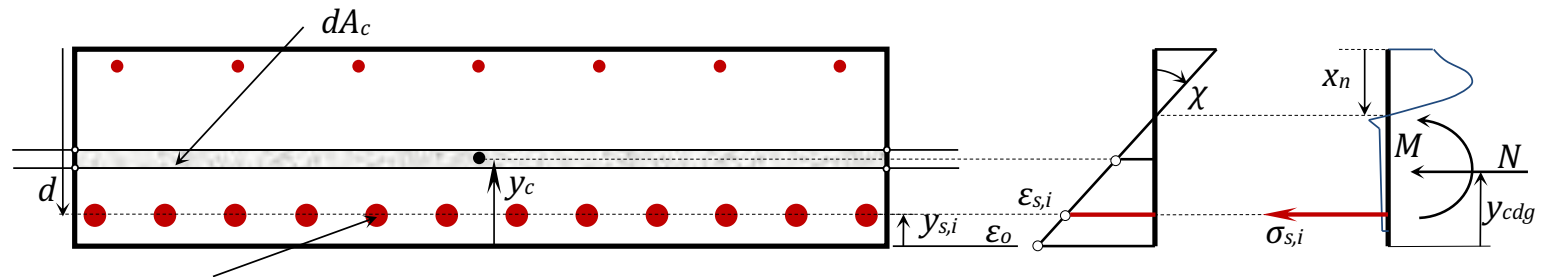

$A_{s, i}$
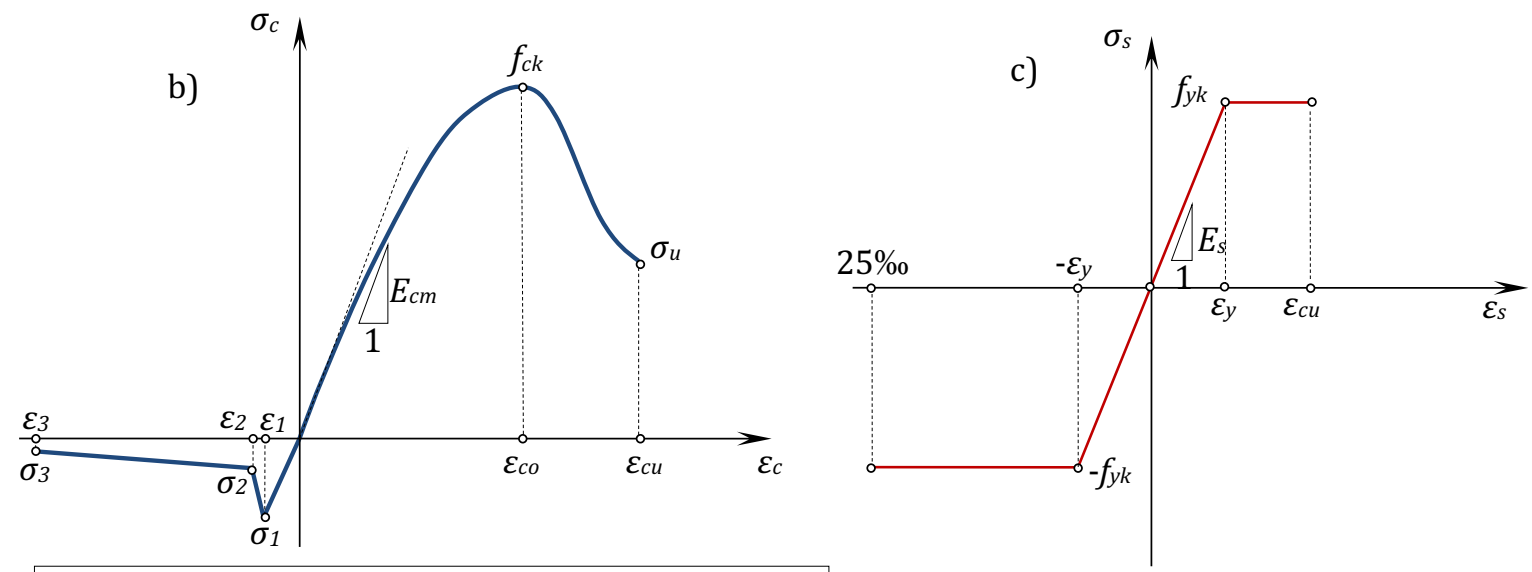

$$
\begin{array}{rlrl}
\sigma_{1}=0.7 f_{c t m, f l}(1.6-d) & \varepsilon_{1} & =\sigma_{1} / E_{c m} \\
\sigma_{2}=0.45 f_{R, 1} k_{h} & \varepsilon_{2} & =\varepsilon_{1}+0.1 \% 0 \\
\sigma_{3}=0.37 f_{R, 4} k_{h} & \varepsilon_{3}=25 \% 0 \\
& & \\
k_{h}=1.0-0.6 \frac{h[\mathrm{~cm}]-12.5}{47.5} \mid & |12.5 \leq h<60|
\end{array}
$$

Parameters proposed by

RILEM TC 162-TDF, 2003

Fig. 3. (a) Sectional discretization; (b) SFRC and (c) steel bar constitutive equations.

\section{EXAMPLES OF APPLICATION}

\subsection{Fontsanta-Trinitat}

\subsubsection{Project Overview}

It consists of a tunnel for the transportation of desalinated water from the Llobregat River toward the Ter River. For this purpose, a main station was built in Fontsanta (Sant Just d'Esvern, Barcelona), which pumps the water toward the Distributing Station of Trinidad (Barcelona) by means a concrete pipe with an internal diameter of $1800 \mathrm{~mm}$. The flow is $2.0 \mathrm{~m}^{3} / \mathrm{s}$ in the first stage, but it is expected to reach up to $3.6 \mathrm{~m}^{3} / \mathrm{s}$ in the future.

The tunnel was excavated under the Collserola Mountain (Barcelona) simultaneously from two opposite fronts (Riera de Sant Just and La Trinidad) using two double-shielded TBMs (Nguyen, 2006) with an internal diameter of $6.0 \mathrm{~m}$. Likewise, three service galleries were built to facilitate intermediate access, ventilation and emergency exits.

The layout gets across heterogeneous soil with several different geological formations. The predominant materials are schist and phyllite (35\% of the length), slate and quartzite slate $(15 \%)$, being the latter ones the worst concerning its geotechnical quality. On the contrary, the rest of the formations are rocks with medium-high quality (granodiorite, hornfels, porphyr, quartzite and metamorphic rocks).

Taking into account the geotechnical characteristics of the ground and the excavation method used, a universal ring (see Fig. 4) with an internal diameter of $5.2 \mathrm{~m}$ consisting of $5+1$ precast segments with a thickness of $0.25 \mathrm{~m}$ and a width of $1.40 \mathrm{~m}$ was designed. Two different concrete strength classes were used in order to adequately face the different levels of compression which could be reached during the service life of the structure. In that sense, a concrete C30/37 (see RILEM TC 162-TDF, 2003) was used in for the precast segments (PS-30) in those stretches where the presence of the phreatic level was not expected. On the contrary, a C50/60 concrete (PS-50) was chosen to resist the high compressive stresses attributable to the poor quality of the rock mass as well as the presence of the phreatic level expectable in a few stretches according to the geotechnical analyzes. 
The design stages considered in the analysis were: (1) curing operations, (2) storage, (3) transport, (4) assembling tasks and (5) the soil pressure during service stage. Concerning the analysis of stage 5, the calculation was performed by means of a 3D-FEM developed with the commercial code FLAC3D (ITG Inc., 2006). The tunnel construction method, the concrete rings as well as the grouting process were simulated taking into account the soil-structure interaction and the possible presence of water.

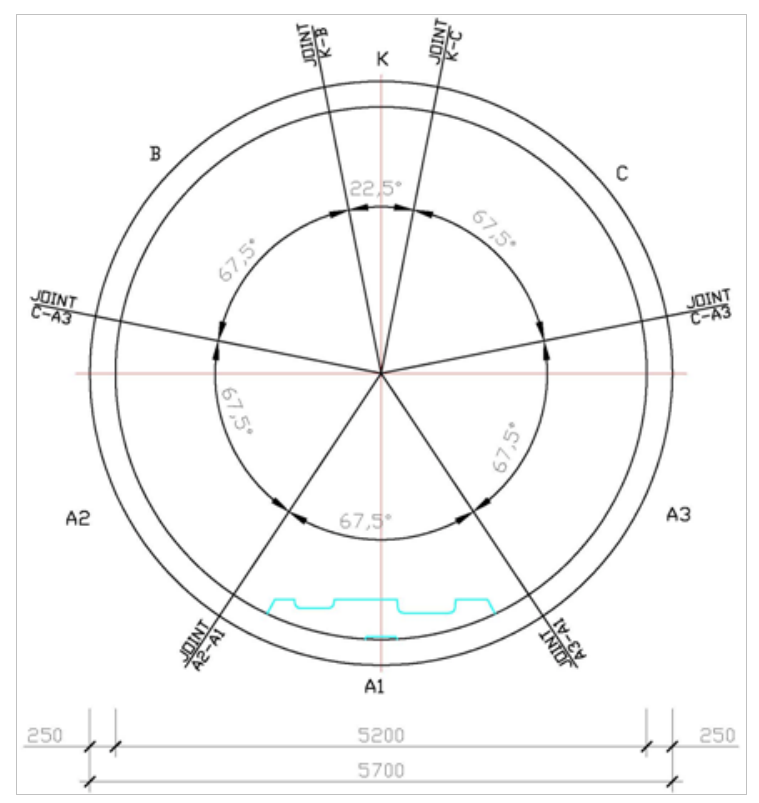

Fig. 4. Main measures (in mm) of the transversal section of the FontSanta-Trinitat tunnel.

The length of the shield $(11.2 \mathrm{~m})$ was considered proportional to the length of the ring $(1.4 \mathrm{~m})$ in the 3D FEM model. Likewise, the model dimensions are $140.0 \mathrm{~m}$ in the axial direction of the tunnel and $64.0 \mathrm{~m}$ in the other two directions (see Fig. 5), considering a uniformly distributed load to simulate the rest of the soil up to covers of $205 \mathrm{~m}$ and $325 \mathrm{~m}$. The model has been discretized in the direction of the tunnel in elements with a length of $1.4 \mathrm{~m}$, corresponding to the length of each of the rings.

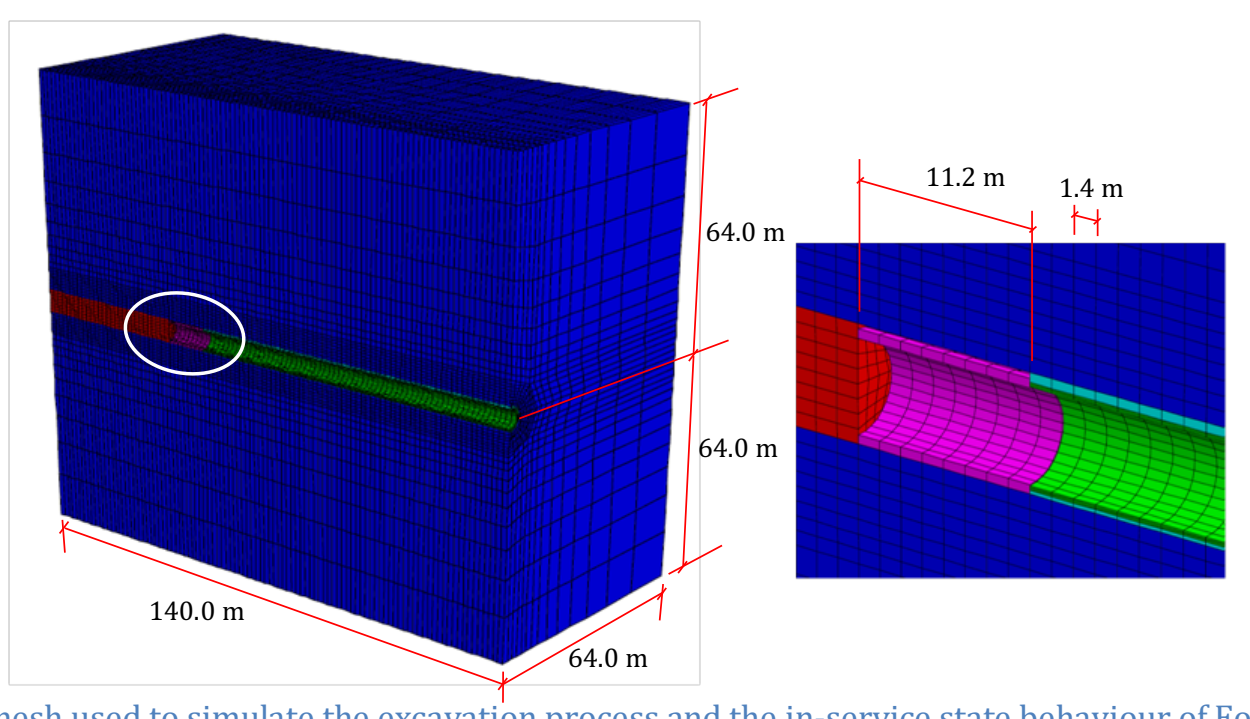

Fig. 5. FE mesh used to simulate the excavation process and the in-service state behaviour of FontSantaTrinitat Tunnel.

Specifically, the two worst scenarios were analyzed: (1) slates formation (specific weight $\gamma_{r}=27.5$ $\mathrm{kN} / \mathrm{m}^{3}$, cohesion $\boldsymbol{c}_{r}=556.10^{-3} \mathrm{~N} / \mathrm{mm}^{2}$, friction angle $\boldsymbol{\Phi}_{r}=33.8^{\circ}$, Young modulus $\boldsymbol{E}_{r}=2277 \mathrm{~N} / \mathrm{mm}^{2}$, Poisson ratio $v_{r}=0.25$ ) with $205 \mathrm{~m}$ of soil cover and with no water presence for the PS-30 and (2) porphyr dike formation $\left(\gamma_{r}=26.8 \mathrm{kN} / \mathrm{m}^{3}, \boldsymbol{c}_{r}=1162.10^{-3} \mathrm{~N} / \mathrm{mm}^{2}, \boldsymbol{\Phi}_{r}=43.6^{\circ}, \boldsymbol{E}_{r}=2636 \mathrm{~N} / \mathrm{mm}^{2}, \boldsymbol{v}_{r}=0.30\right)$ with a cover of $325 \mathrm{~m}$ and considering a water column with a height of $120 \mathrm{~m}$ for the PS-50 precast segment. In any case soil stress relaxation has been considered. Likewise, an earth pressure coefficient $\left(K_{o}\right)$ of 1.5 has been taken into account in both simulations. 
The characteristic and design values of the axial and bending forces obtained in the five stages (see Table 2) are low in relation with the dimensions of the cross section of the segment. However, a minimum amount of reinforcement consisting of 10Ф10 (see Fig. 6a) and 10Ф12 (see Fig. 6b) for SL-30 and for SL50 , respectively, was placed to avoid the brittle failure. Taking these factors into account, it was decided that the reinforcement could be optimized by using a RC-SFRC configuration, with the aim of reaching the benefits previously mentioned.

Table 2. Characteristic and design values for the forces at each of the stages.

\begin{tabular}{|c|c|c|c|c|c|}
\hline \multicolumn{2}{|c|}{ Stage } & $N_{k}(\mathrm{kN})$ & $M_{k}(\mathrm{mkN})$ & $N_{d}(\mathrm{kN})$ & $M_{d}(\mathrm{mkN})$ \\
\hline \multicolumn{2}{|c|}{ Curing (1) } & 0 & 11 & 0 & 21 \\
\hline \multicolumn{2}{|c|}{ Storage (2) } & 0 & 10 & 0 & 20 \\
\hline \multicolumn{2}{|c|}{ Transport (3) } & 0 & 11 & 0 & 21 \\
\hline \multicolumn{2}{|c|}{ Handling (4) } & 0 & 11 & 0 & 21 \\
\hline \multirow{2}{*}{ Service (5) } & SL-30 & 1059 & 9 & 1588 & 13 \\
\hline & SL-50 & 3070 & 8 & 4604 & 11 \\
\hline
\end{tabular}

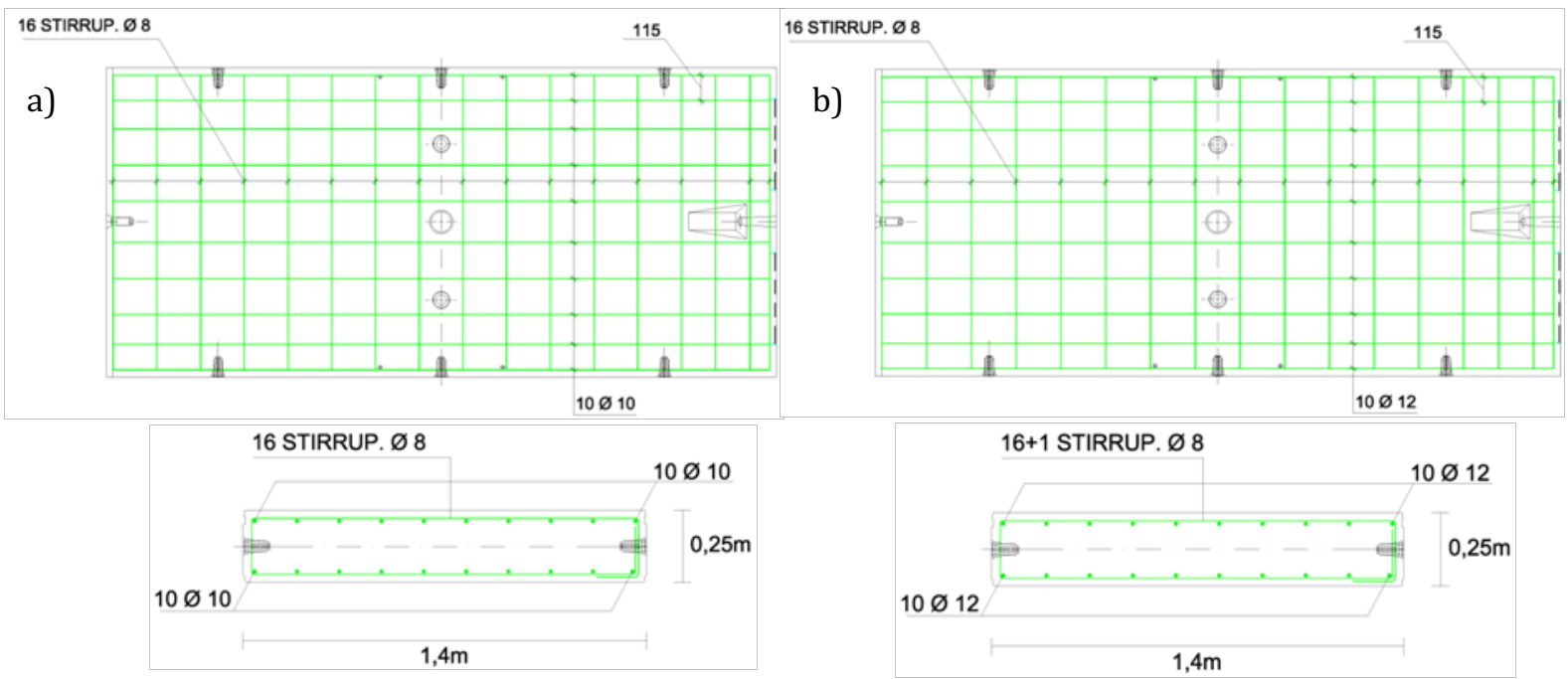

Fig. 6. Longitudinal and transversal conventional reinforcement cages used for: (a) precast segment PS-30 and (b) precast segment PS-50.

Since this was a pilot experience, ten rings with the new RC-SFRC proposed below were manufactured. They were placed in a stretch where the installation conditions and the service structural requirements were representative of the average characteristics of the tunnel.

\subsubsection{Design accounting for the structural contribution of fibers}

The results obtained with the model AES showed that that neither bottom nor upper fibers of the concrete section analyzed (see Figs. $6 \mathrm{~b}$ and $6 \mathrm{c}$ ) reach the characteristic flexural strength $\left(f_{c t k, f l}\right)$ in any of the transitory stages (stages 1 to 4 ), while in service (stage 5) is totally compressed. Therefore the section was not expected to crack.

Bearing in mind this fact, the strategy proposed in this document to design the new RC-SFRC precast segment consists in obtaining the minimum content of reinforcement (steel rebars plus fibres) that assure a ductile failure for the hypothetical situation of reaching the cracking bending force $\boldsymbol{M}_{\boldsymbol{c}}$ in any of the transitory stages. Thus, it was established that $\boldsymbol{M}_{\boldsymbol{c}}$ should be strictly equal to $\boldsymbol{M}_{u}$ (see Eq. 4 and Fig. 7). This approach was proposed for RC sections in (Levi, 1985) and successfully used in (Chiaia et al., 2009a; Chiaia et al., 2009b and Plizzari and Tiberti, 2006) for the optimal design of RC-SFRC segments.

To accomplish this goal, it is necessary to solve the Eq. 4. For RC sections, this equation is linear and can be solved analytically. Otherwise, a nonlinear system is obtained when Eqs. 1-4 are combined for SFRC or RC-SFRC sections, and then the numerical model AES previously introduced has to be used to solve it. 


$$
M_{c r}=M_{u}
$$

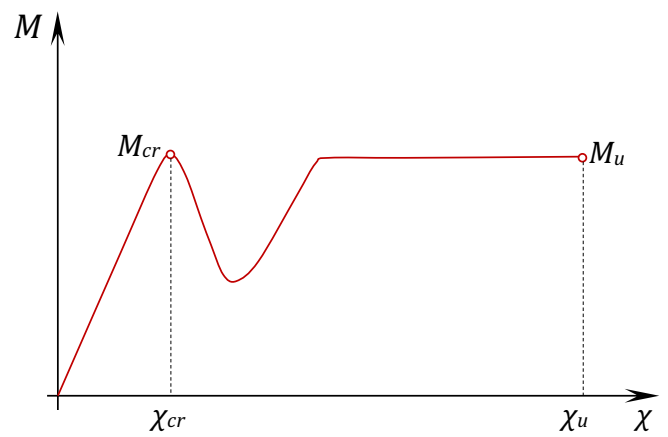

Fig. 7. $M-\chi$ diagram for an optimized RC-SFRC section with ductile failure.

In the same way proposed in (Plizzari and Tiberti, 2006) for the RC-SFRC precast segments of the Line 1 Subway of Valencia (Venezuela), two groups of stirrups where maintained along the two longer sides in order to confine the concrete in this zone. This reinforcement configuration could reduce the splitting cracks that may occur due to the compressive stresses expected during the thrust of the jacks and in the radial joints in-service conditions. With the aim of comparison, in Fig. 8 a the reinforcement cage initially projected for the segment PS-50 is showed, while in Fig. 8b the steel stirrups maintained for the RC-SFRC solution are also showed. It can be noted that the optimized solution proposed (Fig. 8b) presents a considerable reduction of the conventional reinforcement (70\%) with regard to the initial one (Fig. 8a).

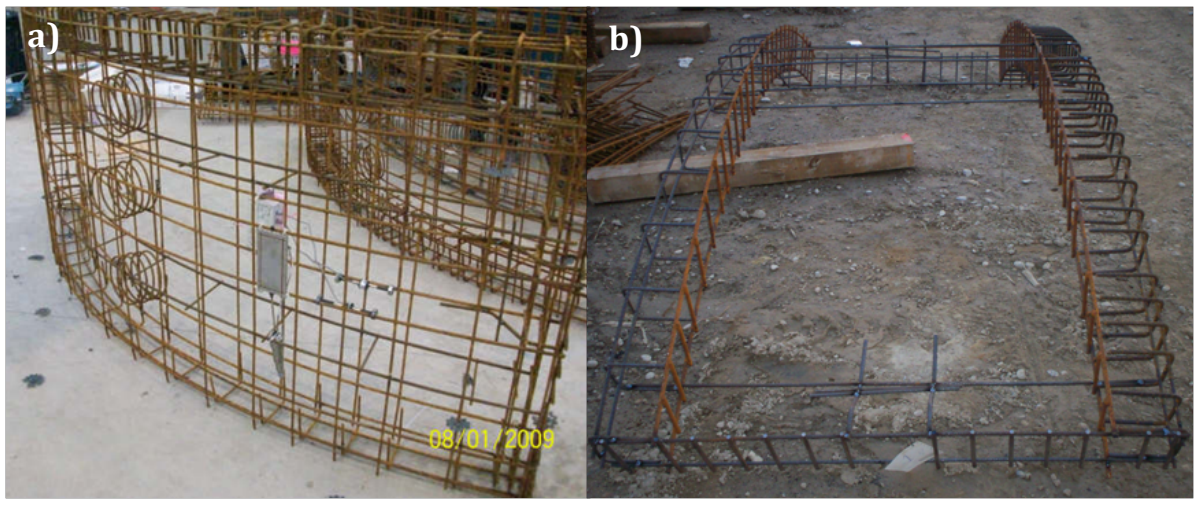

Fig. 8. Reinforcement cages for the precast segments: (a) PS-50 and (b) optimized RC-SFRC segment.

Fig. 9 gathers the RC-SFRC cross section of the segment used for the numerical modelling. The optimum value of $C_{f}$ was determined using the AES model so as to fulfil Eq. 4 . In this respect, the value of $\boldsymbol{M}_{c r}$ for the segment PS-50 (74 mkN) is higher than the one obtained for the segment PS-30 (49 mkN), due to the higher $\boldsymbol{f}_{c t k, f l}$ of the former. Thus, it was decided optimize the value of $\boldsymbol{C}_{f}$ for the precast segment SL50 (concrete strength class C-50/60) and use the same reinforcement configuration for the PS-30 (concrete strength class C-30/37) so as to systematize the construction procedures.

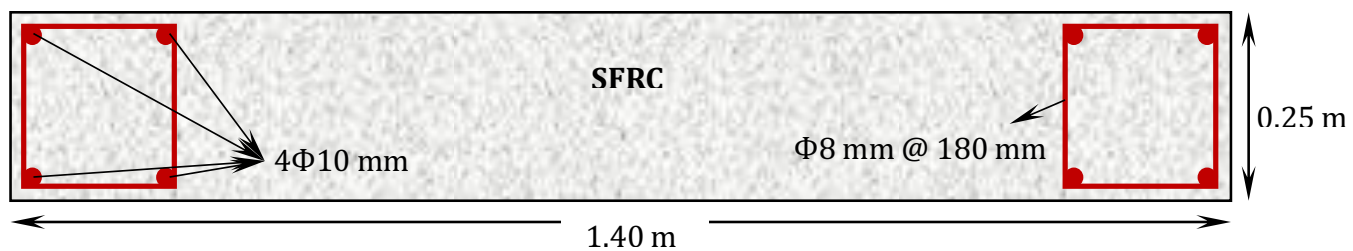

Fig. 9. Steel stirrups used for the RC-SFRC precast segment.

The simulation of post-cracking behaviour of SFRC was dealt with the constitutive equation suggested by the RILEM TC 162-TDF (2003) (see Fig. 3b). However, at this stage of the design process neither data of the fibre content which was going to be used in the concrete nor results from characterization tests of SFRC tension behaviour were available. Alternatively, Eqs. 5 and 6 proposed by Barros et al., (2005) were used for the calculation of the residual flexural strength $\left(f_{R, i}\right)$ of SFRC as a function of $C_{f}$. These expressions were calibrated on basis of the results obtained in bending tests of prismatic beams of SFRC with same hooked-end steel fibres used in the optimized RC-SFRC precast segments analyzed in this work (length $\boldsymbol{l}_{\boldsymbol{f}}=$ 
$60 \mathrm{~mm}$, diameter $\boldsymbol{d}_{f}=0.75$, Young modulus $\boldsymbol{E}_{f}=210000 \mathrm{~N} / \mathrm{mm}^{2}$ and a failure tensile strength $f_{f u}=1100$ $\mathrm{N} / \mathrm{mm}^{2}$ ).

$$
\begin{aligned}
& f_{R, 1}=0.0945 C_{f}+0.702 \\
& f_{R, 4}=0.0926 f_{R, 1}
\end{aligned}
$$

For this study, the values of $C_{f}$ adopted range between $0 \mathrm{~kg} / \mathrm{m}^{3}$ and $40 \mathrm{~kg} / \mathrm{m}^{3}$. The latter value is motivated by economic criteria. Table 3 gathers the numerical values of the parameters used to simulate the post-cracking behaviour of SFRC.

Table 3. Values of $\sigma_{i}$ and $\varepsilon_{i}$ used to simulate the post-cracked behaviour of SFRC (C50/60).

\begin{tabular}{|c|c|c|c|c|c|c|c|c|}
\hline $\begin{array}{c}\boldsymbol{C}_{\boldsymbol{f}} \\
\left(\mathrm{Kg} / \mathrm{m}^{3}\right)\end{array}$ & $\begin{array}{c}\boldsymbol{f}_{\boldsymbol{R}, \boldsymbol{1}} \\
\left(\mathrm{N} / \mathrm{mm}^{2}\right)\end{array}$ & $\begin{array}{c}\boldsymbol{f}_{\boldsymbol{R}, \boldsymbol{4}} \\
\left(\mathrm{N} / \mathrm{mm}^{2}\right)\end{array}$ & $\begin{array}{c}\boldsymbol{\sigma}_{\mathbf{1}^{*}} \\
\left(\mathrm{~N} / \mathrm{mm}^{2}\right)\end{array}$ & $\begin{array}{c}\boldsymbol{\varepsilon}_{1} \\
(\mathrm{~mm} / \mathrm{m})\end{array}$ & $\begin{array}{c}\boldsymbol{\sigma}_{\boldsymbol{2}} \\
\left(\mathrm{N} / \mathrm{mm}^{2}\right)\end{array}$ & $\begin{array}{c}\boldsymbol{\varepsilon}_{2} \\
(\mathrm{~mm} / \mathrm{m})\end{array}$ & $\begin{array}{c}\boldsymbol{\sigma}_{\boldsymbol{3}} \\
\left(\mathrm{N} / \mathrm{mm}^{2}\right)\end{array}$ & $\begin{array}{c}\boldsymbol{\varepsilon}_{3} \\
(\mathrm{~mm} / \mathrm{m})\end{array}$ \\
\hline 0 & 0.702 & 0.650 & 4.844 & 0.131 & 0.266 & 0.231 & 0.203 & 25.000 \\
10 & 1.647 & 1.525 & 4.844 & 0.131 & 0.624 & 0.231 & 0.475 & 25.000 \\
20 & 2.592 & 2.400 & 4.844 & 0.131 & 0.982 & 0.231 & 0.748 & 25.000 \\
30 & 3.537 & 3.275 & 4.844 & 0.131 & 1.340 & 0.231 & 1.021 & 25.000 \\
40 & 4.482 & 4.150 & 4.844 & 0.131 & 1.698 & 0.231 & 1.293 & 25.000 \\
\hline
\end{tabular}

$* \sigma_{1}$ was evaluated by means de expression $\sigma_{1}=0.52 f_{c t m}, f(1.6-d)$ proposed by Barros et al. (2005) due to the high values obtained with the one suggested by the RILEM TC 162-TDF (2003).

The mechanical behaviour of the steel rebars has been simulated by considering a bilinear diagram (see Fig. 3c), as well as a value of $500 \mathrm{~N} / \mathrm{mm}^{2}$ for $f_{\boldsymbol{y} k}$ and $210000 \mathrm{~N} / \mathrm{mm}^{2}$ for $\boldsymbol{E}_{\boldsymbol{s}}$.

Fig. 10 shows the $M-\chi$ diagrams $\left(N_{k}=0\right)$ numerically obtained for the RC-SFRC precast segment reinforced with different values of $\boldsymbol{C}_{\boldsymbol{f}}$ and the steel stirrups presented in Fig. 9.

The results presented in Fig. 10 confirm the requirement of using a $C_{f}$ higher than $20 \mathrm{~kg} / \mathrm{m}^{3}$ to fulfil Eq. 4. Particularly, by representing the relation $\boldsymbol{M}_{u}-C_{f}$ (see Fig. 11), it can be deduced the optimum value for $\boldsymbol{C}_{f}$ is closely to $25 \mathrm{~kg} / \mathrm{m}^{3}$.

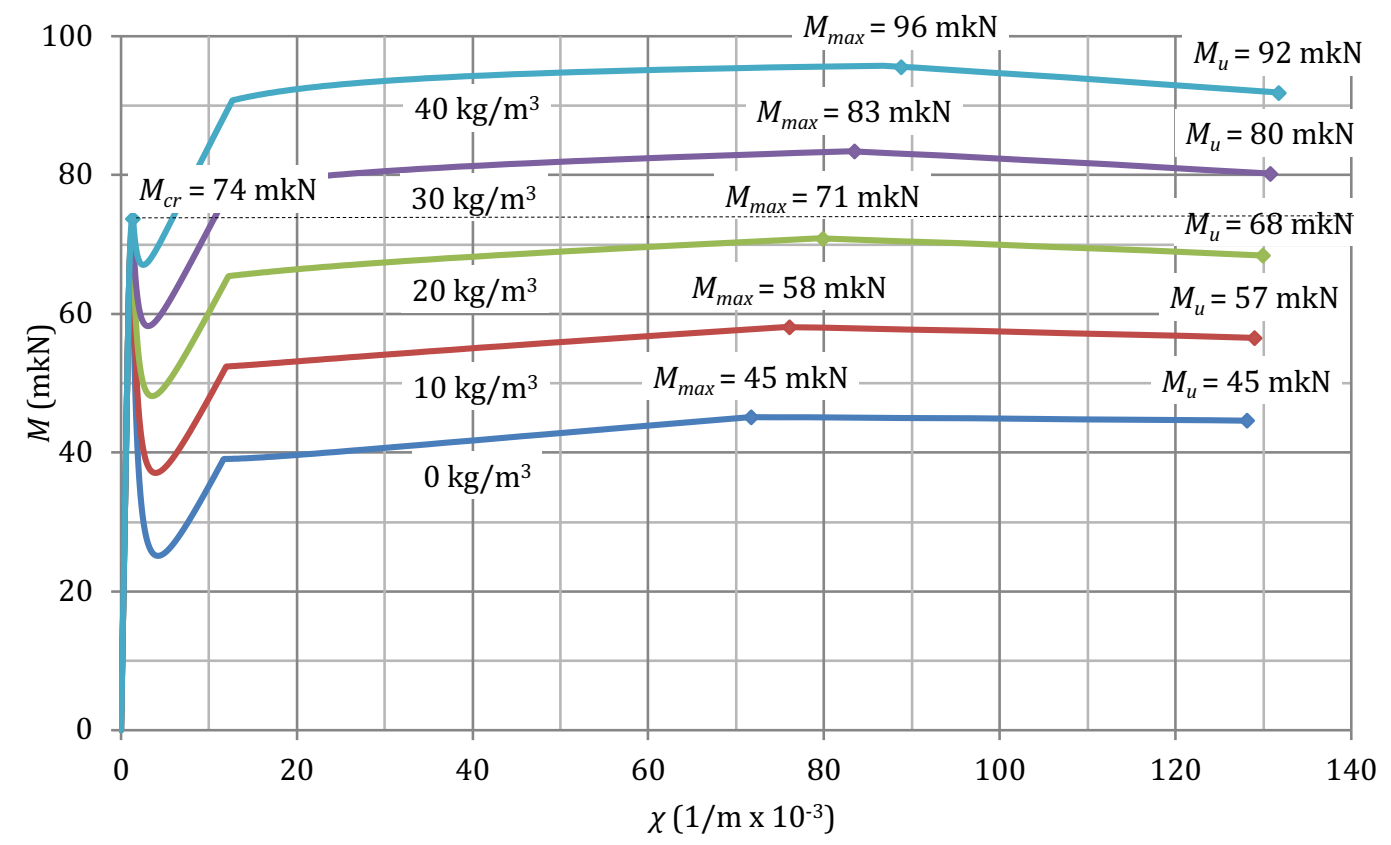

Fig. 10. $M-\chi$ diagrams for the C50/60 concrete strength class RC-SFRC precast segment with different amounts of steel fibres.

It must be remarked that this is the optimum value for $C_{f}$ obtained considering the bending forces $(M)$ and the compression forces $(N)$ presented in Table 2. In this sense, in order to confirm the correctness of this value for the rest of load types, the influence of $\boldsymbol{C}_{\boldsymbol{f}}$ in the behaviour of the precast segment under concentrated loads (thrust of the jacks and serviceability stresses in the joints) must be analyzed. Up to date, several numerical studies (Waal, 1999; Blom 2002; Plizzari and Tiberti, 2006; Burguers et al., 2007 and Kasper et al., 2008; Cavalaro 2009) and some experimental experiences (Caratelli et al., 2010) that 
confirm the excellent response of the fibres in these load cases, have been presented in the international literature. Nevertheless, a systematical methodology has not been proposed yet to find the optimum value of $\boldsymbol{C}_{f}$ considering all the possible load states due to the numerous variables that take part in the study. There is, however, a generally accepted design method that consists in a numerical evaluation of the optimum value of $C_{f}$ by means of a structural analysis considering the forces $(N, M)$ and verifying numerically and/or experimentally that the segmental lining behaves also properly under concentrated loads.

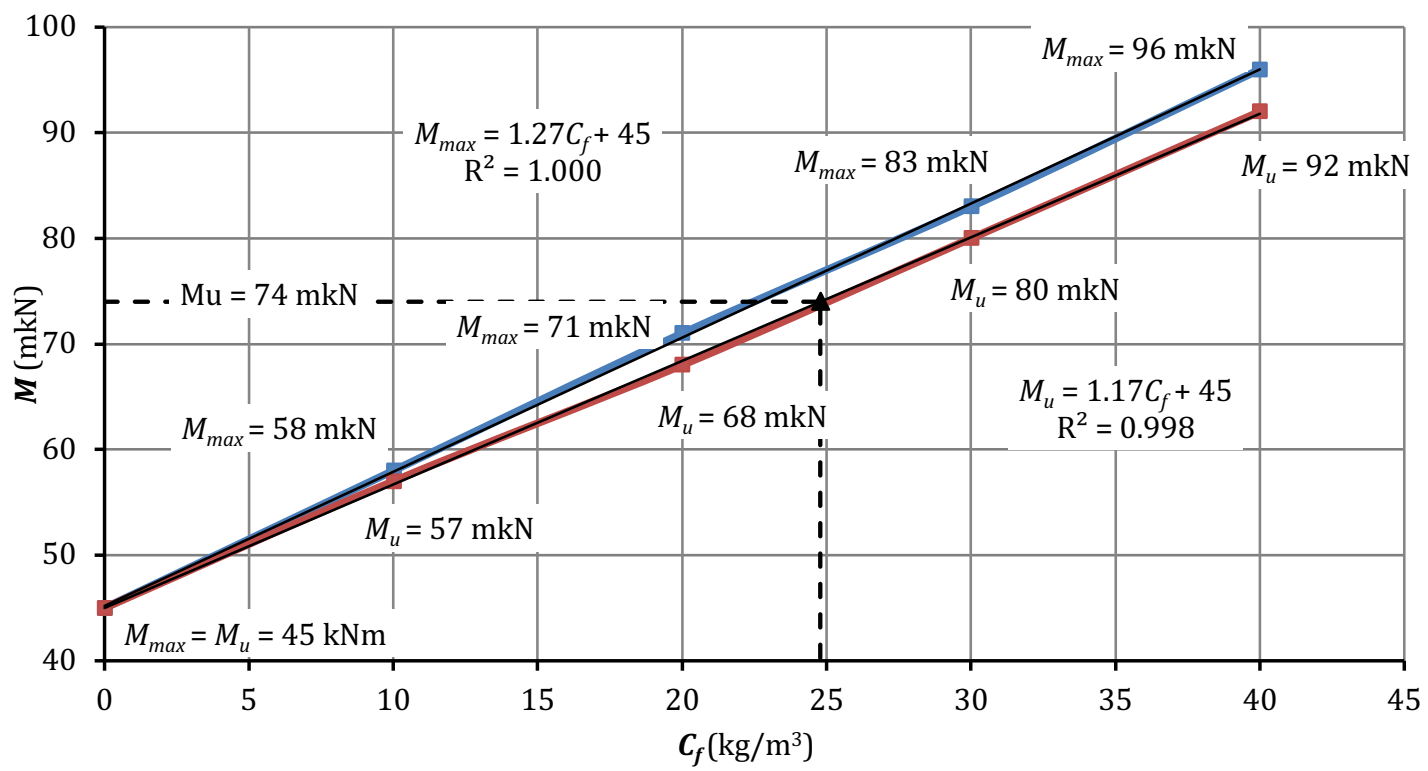

Fig. 11. Increase of $M_{\max }$ and $M_{u}$ with the amount of fibres $C_{f}$.

Considering the above mentioned and the results obtained in the numerical analysis, it was decided to manufacture ten rings with an amount of $25 \mathrm{~kg} / \mathrm{m}^{3}$ of steel fibres together with the reinforcement cage proposed in Fig. $8 \mathrm{~b}$ and Fig. 9. It has to be mentioned that none of the rings presented cracks during the assembling operations neither service loads. This fact confirms that the value of $25 \mathrm{~kg} / \mathrm{m}^{3}$ previously deduced numerically could be the desired optimum value of $C_{f}$ for the geometrical and mechanical boundary conditions simulated fixed in this analysis case.

\subsection{TERRASSA TUNNEL}

\subsubsection{Project Overview}

This case consists in two parallel rail tunnels built in the urban area of Terrassa as the extension of the Ferrocarriles de la Generalitat de Catalunya (FGC). Both tunnels are drilled successively being the total length of each one of $4510 \mathrm{~m}$. The tunnels consist of rings (see Fig. 12) with an internal diameter of $6.0 \mathrm{~m}$ and formed by $6+1$ RC-SFRC precast concrete C30/37 segments with a width of $1.5 \mathrm{~m}$ and a thickness of $0.30 \mathrm{~m}$.

Both tunnels were excavated by means of a TBM with a diameter section of $6.90 \mathrm{~m}$. The existing gap between the segmental lining ring and the drilled soil was $15 \mathrm{~cm}$ wide and it was filled with grout.

The analyzed stretch passes through a soil formed by quaternary clay, with a $24.5 \mathrm{~m}$ cover and with the presence of the phreatic level $9.5 \mathrm{~m}$ above the tunnel crown. In this sense, the numerical simulation of the soil-structure interaction was also carried out with the commercial code FLAC3D (ITG Inc., 2006). For that purpose, a mesh of $150.0 \mathrm{~m}$ wide, $27.5 \mathrm{~m}$ high and $40.0 \mathrm{~m}$ deep with respect to the horizontal axis of the tunnels was generated (see Fig. 13). The elements width in the direction of the tunnel equals the width of the precast segment $(1.5 \mathrm{~m})$. Concerning the material properties, the following parameters were considered: $\gamma_{r}=21.5 \mathrm{kN} / \mathrm{m}^{3}, \boldsymbol{c}_{r}=30.10^{-3} \mathrm{~N} / \mathrm{mm}^{2}, \boldsymbol{\Phi}_{r}=25.0^{\circ}, \boldsymbol{E}_{r}=84 \mathrm{~N} / \mathrm{mm}^{2}, \boldsymbol{v}_{r}=0.30$. Likewise, a coefficient $K_{o}=1.3$ was adopted to take into account the possibility of finding overconsolidated soils (according to the geotechnical reports). 


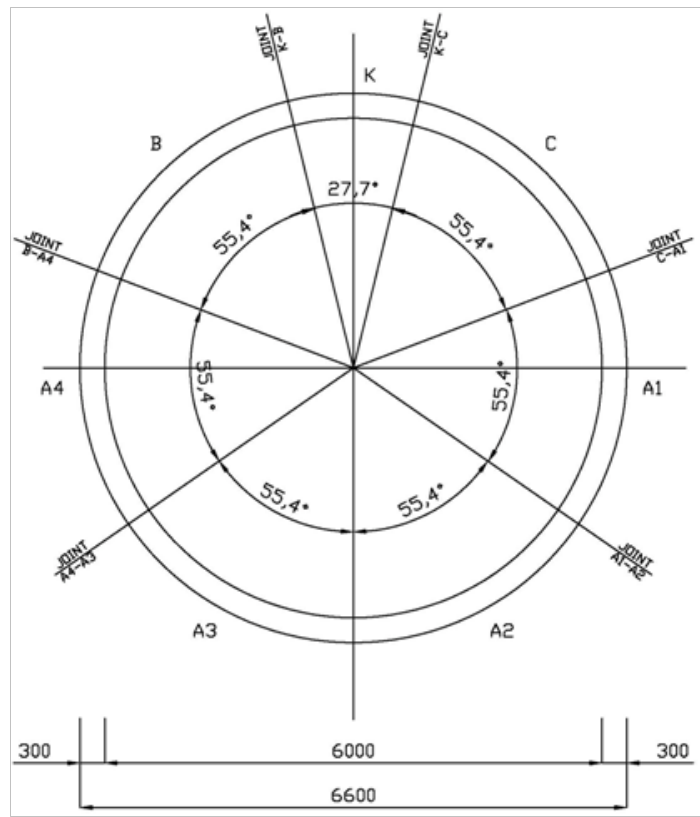

Fig. 12. Main measures (in m) of the transversal section of the Terrassa Tunnel.
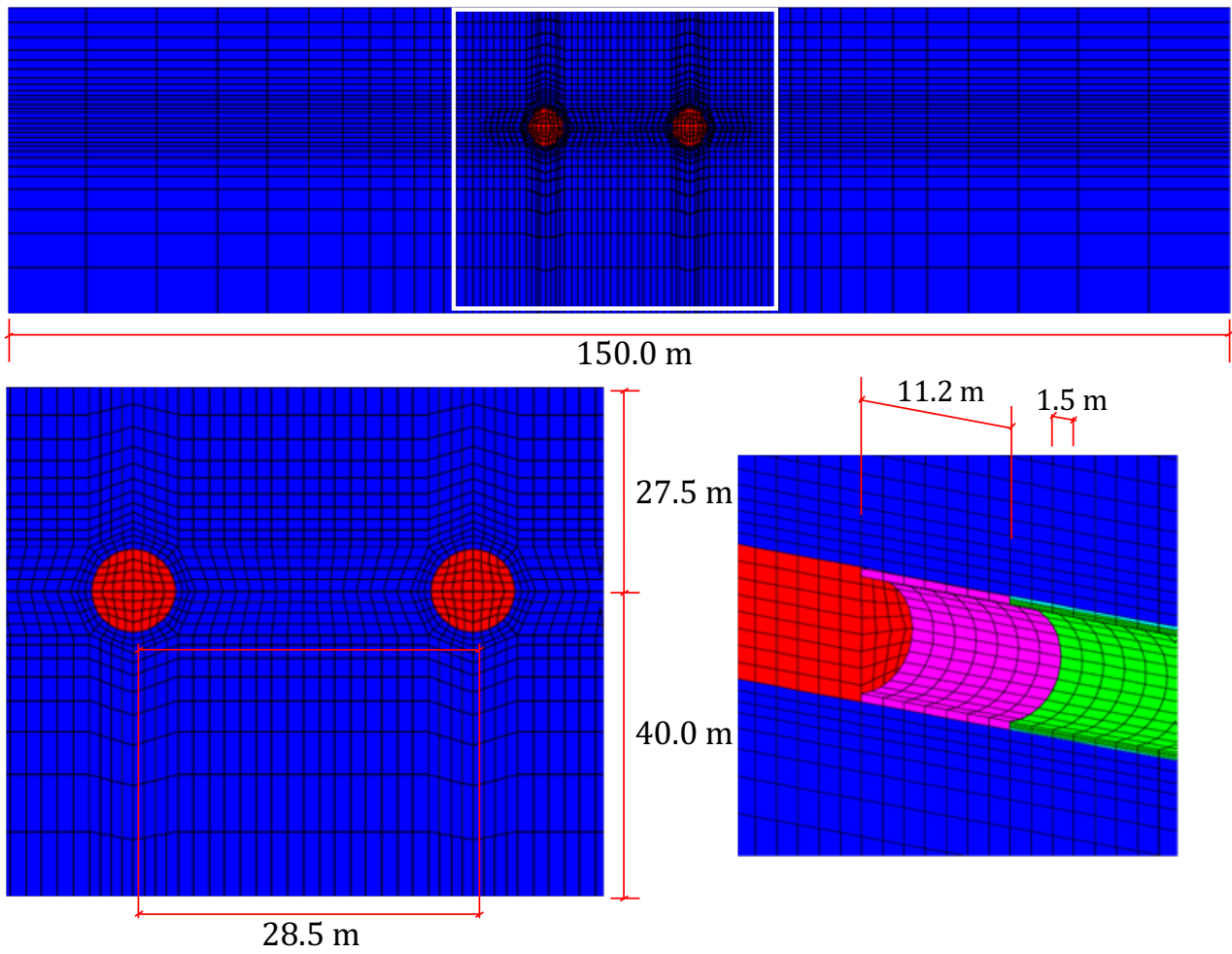

Fig. 13. FE mesh used to simulate the excavation process and the in-service state behaviour for the Terrassa Tunnel.

Table 4 presents the characteristic and design values of $\boldsymbol{N}$ and $\boldsymbol{M}$ obtained for the transitory stages (curing, storage, transport and handling) and the service stage (5), being the latter the most adverse in terms of the design of the reinforcement.

In order to resist the forces presented in Table 4, an initial RC-SFRC precast segment with $15 \Phi 12$ in each side (see Fig. 14) plus $25 \mathrm{~kg} / \mathrm{m}^{3}$ of fibres was proposed in the project, though the structural contribution of the fibres were not taken into account. The purpose of the fibres in this case was to improve the behaviour under the high expected concentrated loads (thrust of jacks and compressive stresses in the radial joints). 
Table 4. Characteristic and design values for the forces at each of the stages.

\begin{tabular}{|c|c|c|c|c|}
\hline Stage & $N_{k}(\mathrm{kN})$ & $M_{k}(\mathrm{mkN})$ & $N_{d}(\mathrm{kN})$ & $M_{d}(\mathrm{mkN})$ \\
\hline \hline Curing (1) & 0 & 13 & 0 & 19 \\
Storage (2) & 0 & 21 & 0 & 42 \\
Transport (3) & 0 & 21 & 0 & 42 \\
Handling (4) & 15 & 55 & 29 & 110 \\
Service (5) & 2806 & 361 & 4209 & 542 \\
\hline
\end{tabular}

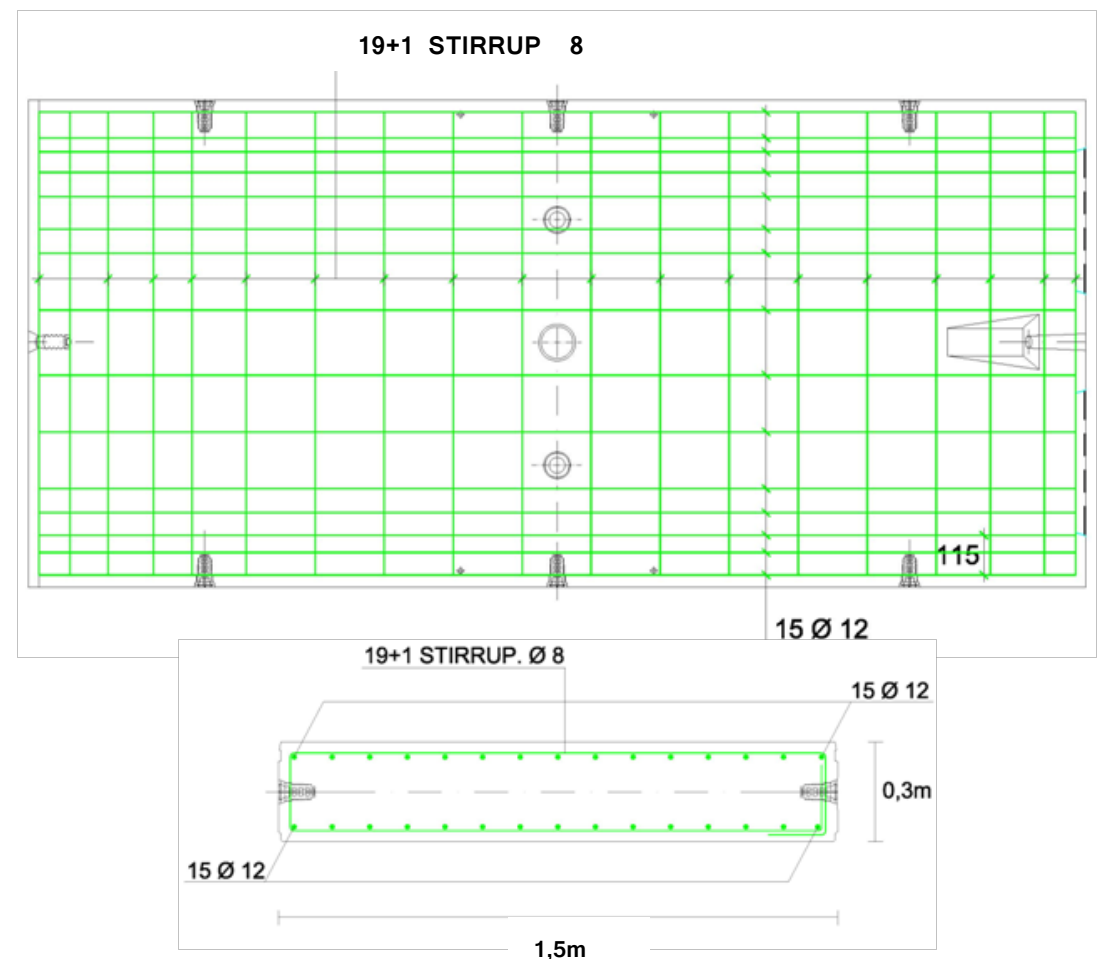

Fig. 14. Steel rebar reinforcement configuration of the segment initially proposed in the project.

\subsubsection{Design accounting for the structural contribution of fibers}

Similarly to the first case analyzed, a steel rebar reinforcement cage consisting of $11 \Phi 12$ and stirrups $\Phi 8$ each $25 \mathrm{~cm}$ was established (see Fig. 15) to subsequently iterate with different $C_{f}(0,15,25$ and 30 $\mathrm{kg} / \mathrm{m}^{3}$ ) until the design condition was fulfilled.

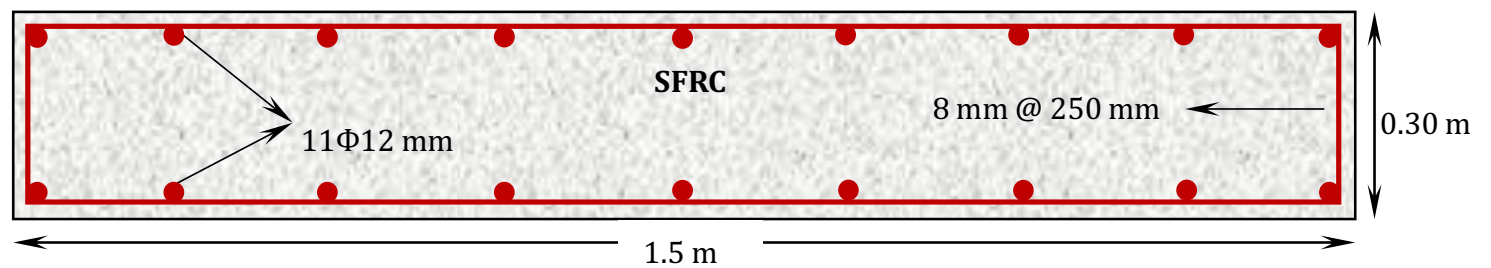

Fig. 15. Optimum RC-SFRC precast segment proposed.

In this case, the service stage (5) leads to the most unfavourable stress-strain conditions. The precast segment is subjected to a high axial load $N_{d}$ with a concomitant $M_{d}$ which cracks the section. Thus, the amount of reinforcement resulting from imposing Eq. 4 would be insufficient and, therefore, would not be on the side of safety. Hence, the classical criterion of optimum in ULS design was used, which consists in fixing $N_{d}$ and impose Eq. 7. Likewise, once the optimum value of $C_{f}$ was obtained, it was verified that $\boldsymbol{W}_{k}$ was lower than the $\boldsymbol{w}_{\max }=0.3 \mathrm{~mm}$ established in the basis of the project.

$$
M_{u}=M_{d}
$$


Once again, since no previous experimental data about SFRC for the different values of $C_{f}$ was available, Eqs. 5 and 6 were used with the aim of defining the parameters (see Table 5) of the constitutive equation chosen (see Fig. 3b) for simulating the post-cracking behaviour of SFRC class C30/37.

Table 5. Values of $\sigma_{i}$ and $\varepsilon_{i}$ used to simulate the post-cracked behaviour of SFRC (C30/37).

\begin{tabular}{|c|c|c|c|c|c|c|c|c|}
\hline $\begin{array}{c}\boldsymbol{C}_{\boldsymbol{f}} \\
\left(\mathrm{Kg} / \mathrm{m}^{3}\right)\end{array}$ & $\begin{array}{c}\boldsymbol{f}_{\boldsymbol{r}, \boldsymbol{1}} \\
\left(\mathrm{N} / \mathrm{mm}^{2}\right)\end{array}$ & $\begin{array}{c}\boldsymbol{f}_{\boldsymbol{r}, \boldsymbol{4}} \\
\left(\mathrm{N} / \mathrm{mm}^{2}\right)\end{array}$ & $\begin{array}{c}\boldsymbol{\sigma}_{1}{ }^{*} \\
\left(\mathrm{~N} / \mathrm{mm}^{2}\right)\end{array}$ & $\begin{array}{c}\boldsymbol{\varepsilon}_{\boldsymbol{1}} \\
(\mathrm{mm} / \mathrm{m})\end{array}$ & $\begin{array}{c}\boldsymbol{\sigma}_{2} \\
\left(\mathrm{~N} / \mathrm{mm}^{2}\right)\end{array}$ & $\begin{array}{c}\boldsymbol{\varepsilon}_{2} \\
(\mathrm{~mm} / \mathrm{m})\end{array}$ & $\begin{array}{c}\boldsymbol{\sigma}_{3} \\
\left(\mathrm{~N} / \mathrm{mm}^{2}\right)\end{array}$ & $\begin{array}{c}\boldsymbol{\varepsilon}_{3} \\
(\mathrm{~mm} / \mathrm{m})\end{array}$ \\
\hline 0 & 0.702 & 0.650 & 3.245 & 0.101 & 0.246 & 0.201 & 0.187 & 25.000 \\
15 & 2.120 & 1.963 & 3.245 & 0.101 & 0.743 & 0.201 & 0.566 & 25.000 \\
25 & 3.065 & 2.838 & 3.245 & 0.101 & 1.074 & 0.201 & 0.818 & 25.000 \\
30 & 3.537 & 3.275 & 3.245 & 0.101 & 1.240 & 0.201 & 0.944 & 25.000 \\
\hline
\end{tabular}

$* \sigma_{1}$ was evaluated by means de expression $\sigma_{1}=0.52 f_{c t m, f l}(1.6-d)$ proposed by Barros et al. (2005) due to the high values obtained with the one suggested by the RILEM TC 162-TDF (2003).

The response of the steel rebars was dealt with the diagram of Fig. 3 c, assigning $f_{y k}=500 \mathrm{~N} / \mathrm{mm}^{2}$ and $E_{s}=210000 \mathrm{~N} / \mathrm{mm}^{2}$.

Fig. 16 shows the $\boldsymbol{N}_{u^{-}} \boldsymbol{M}_{u}$ interaction diagram for the section with the RC-SFRC precast segment defined in Fig. 15 with values of $C_{f}$ ranging between 0 and $30 \mathrm{~kg} / \mathrm{m}^{3}$.

On the basis of the results gathered in Fig. 16, it is observed that with a $C_{f}$ of $15 \mathrm{~kg} / \mathrm{m}^{3}$, the $\boldsymbol{M}_{\boldsymbol{d}}$ of 542 mkN (see Table 4) is already exceeded. Likewise, it should be noted that the maximum increase of $\boldsymbol{M}_{u}$ does not exceed 5\% (RC-SFRC with $C_{f}=30 \mathrm{~kg} / \mathrm{m}^{3}$ ) with regard to the RC precast segment $\left(C_{f}=0 \mathrm{~kg} / \mathrm{m}^{3}\right)$ if $\boldsymbol{N}_{\boldsymbol{d}}=$ $4209 \mathrm{kN}$. In other words, in this case the rebars perform the main resistance function in failure, whereas the fibers play a more important role in the crack width control.

Fig. 17 shows the $\boldsymbol{M}_{\boldsymbol{u}}-\boldsymbol{C}_{f}$ and $\boldsymbol{M}_{0.3 \mathrm{~mm}} \boldsymbol{C}_{f}$ curves numerically obtained by fixing $\boldsymbol{N}_{\boldsymbol{d}}=2806 \mathrm{kN}$, highlighting that: (1) both curves can be excellently well approximated with straight tendencies; (2) ULS is the most unfavourable state, however just a minimum of $7 \mathrm{~kg} / \mathrm{m}^{3}$ is required in order to verify Eq. 7; and (3) the growth rate of $\boldsymbol{M}_{0.3 \mathrm{~mm}}\left(1.22 \mathrm{mkN} / \mathrm{kg} / \mathrm{m}^{3}\right)$ is a $42 \%$ higher than that of $\boldsymbol{M}_{u}\left(0.86 \mathrm{mkN} / \mathrm{kg} / \mathrm{m}^{3}\right)$, proving the higher effectiveness of the fiber for loads in the SLS in comparison with ULS.

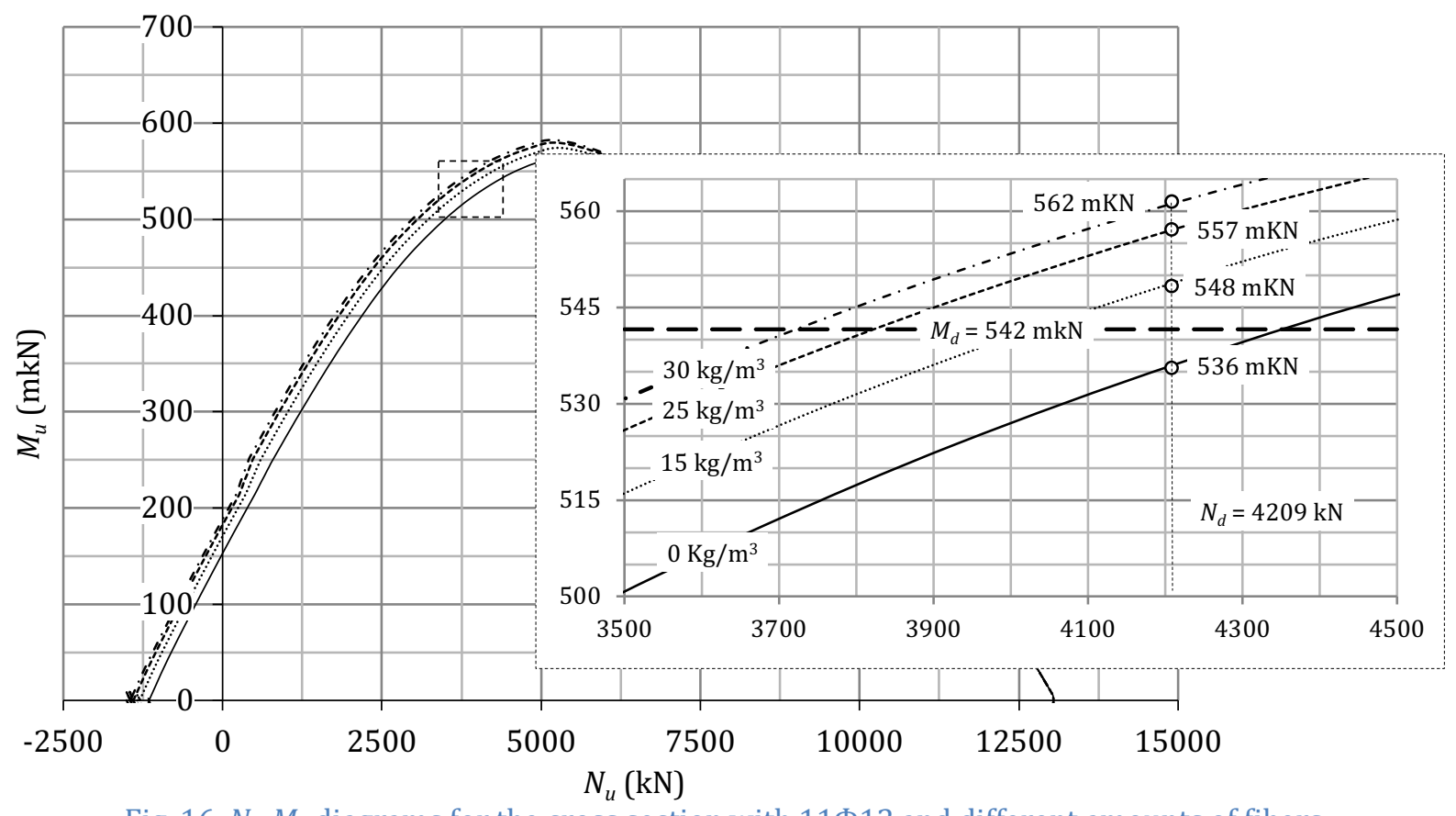

Fig. 16. $N_{u}-M_{u}$ diagrams for the cross section with $11 \Phi 12$ and different amounts of fibers.

Finally, it was suggested the use of the same $C_{f}$ of $25 \mathrm{~kg} / \mathrm{m}^{3}$ established in the project together with the steel rebar cage presented in Fig. 15 (which represents a reduction around the 38\% of the conventional reinforcement comparing with the initial solution gathered in Fig. 14), in opposition to the optimum value of $7 \mathrm{~kg} / \mathrm{m}^{3}$ obtained numerically. This decision was made for several reasons: (1) it is unusual to work with such low values of $C_{f}$ and (2) that the previous experiences indicate that a minimum amount of 20 $\mathrm{kg} / \mathrm{m}^{3}$ is required for the control of the possible cracking due to the effect of concentrated loads. 


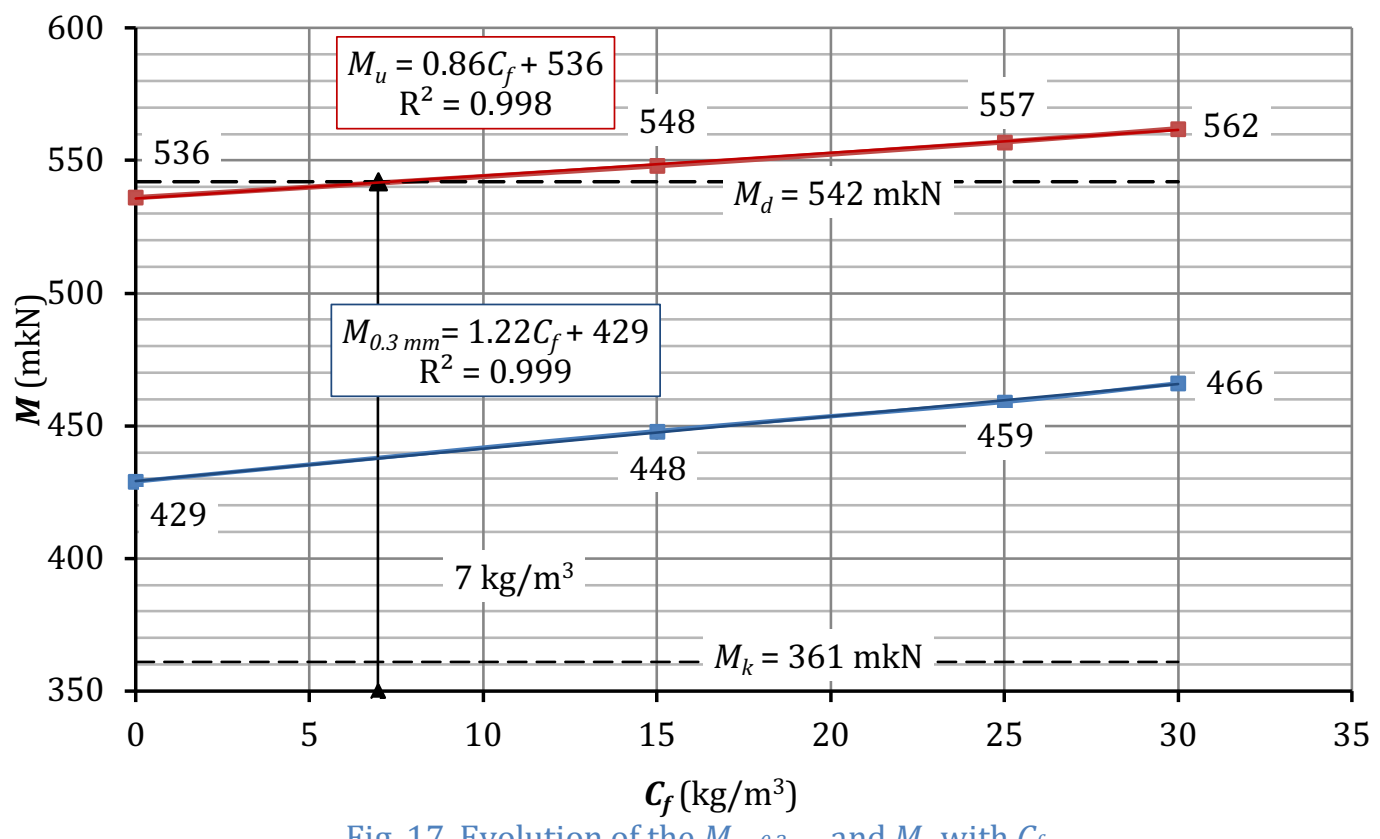

\section{CONCLUSIONS}

A summary that includes the main worldwide applications of SFRC in precast segmental linings as well as a design methodology for the optimization of the reinforcement taking into account the structural contribution of the fibres have been presented.

To highlight both the advantages of using fibres and the suitability of the design methodology described, two real experiences carried out in Barcelona in which SFRC has been used in the tunnel segments have been presented. The reached conclusions are:

- The use of both fibres and a minimum amount of steel rebars is an ideal alternative to enhance the behaviour of the segments to the thrust of the jacks and avoid cracking during this operation.

- When the design forces are relatively low in comparison with the segment cross-section dimension, the use of fibres can lead to a significant reduction (up to 70\%) of the steel rebars, remaining the concrete confining stirrups as the only passive reinforcement.

- In cases when design forces are moderate, the required amount of fibres to resist them can be economically unfeasible as the case of Terrassa Tunnel. Alternatively, the combined solution of fibres and rebars can be used. With this the fibres work from the onset of cracking, controlling its width and spacing, while the rebars take on the main resistant function.

One experimental stretch consisting of ten RC-SFRC precast pilot rings with an optimum reinforcement configuration (two edge stirrups $\Phi 8 \mathrm{~mm} @ 180 \mathrm{~mm}+25 \mathrm{~kg} / \mathrm{m}^{3}$ of steel fibres) has been carried out in the FontSanta Trinitat tunnel. Likewise, the RC-SFRC precast segment proposed for the Terrassa Tunnel (11Ф12 in each side +1 stirrup $\Phi 8 \mathrm{~mm} @ 250 \mathrm{~mm}+25 \mathrm{~kg} / \mathrm{m}^{3}$ of steel fibres) has been presented. However, the RC-SFRC precast segmental lining initially designed in the project (for which the contribution of the steel fibres was not considered) was finally used. The obtained results were excellent at a production level (reducing times and risks during the manufacture) as well as in efficiency rates (decreasing significantly the problems related to impact and the thrust of jacks) thanks to the use of fibres.

These satisfying results have motivated the appearance of new tunnelling projects in which the use of fibres is being taken into account as a reinforcement material for concrete.

\section{ACKNOWLEDGEMENTS}

The authors of this paper want to acknowledge the economical support provided in order to develop the study of the FontSanta-Trinitat Tunnel (FCC Construcción, S.A., OHL, S.A., and COPISA, S.A.) and the Terrassa Tunnel (FCC Construcción, S.A., OHL, S.A., and COPISA, S.A.). Likewise, this work has been possible thanks to the economical support received of the Research Project BIA2010-17478: Procesos constructivos mediante hormigones reforzados con fibras. 


\section{REFERENCES}

Angerer, W., Chappell, M., 2008. Design of steel fibre reinforced segmental lining for the gold coast desalination tunnels. In: $13^{\text {th }}$ Australian Tunneling Conference, Melbourne (Australia), May 4-7, pp. 263-470.

Barros, J.A.O., Figueiras, J.A., 1999. Flexural behaviour of SFRC: Testing and modeling. ASCE Journal of Materials in Civil Engineering 11 (4), 331-339.

Barros, J.A.O., Cunha, V.M.C.F., Ribeiro, A.F., Antunes, J.A.B., 2005. Post-cracking behaviour of steel fibre reinforced concrete. RILEM Materials and Structures 38 (1), 47-56.

Bencardino, F., Rizzuti, L., Spadea, G., Swamy, R.N., 2008. Stress-strain behavior of steel fiber-reinforced concrete in compression. ASCE Journal of Materials in Civil Enineering 20 (3), 255-263.

Blanco, A., Pujadas, P., de la Fuente, A., Aguado, A., 2010. Comparative analysis of constitutive models of fibre reinforced concrete. Hormigón \& Acero 61 (256), 83-100. [In Spanish].

Blom, C.B.M., 2002. Design philosophy of concrete linings in soft soils. ISBN 90-407-2366-4, Delft (The Netherlands).

Burguers, R., Walraven, J., Plizzari, G.A., Tiberti, G., 2007. Structural behavior of SFRC tunnel segments during TBM operations. In: World Tunnel Congress ITA-AITES 2007, Prague (Czech Republic), pp. 1461-1467.

Caratelli A, Meda A, Rinaldi Z, Romualdi P., 2010. Structural behavior of precast tunnel segments in fiber reinforced concrete. Tunnelling and Underground Space Technology. [In Press].

Cavalaro, S.H.P., 2009. Aspectos tecnológicos de túneles construidos con tuneladora y dovelas prefabricadas de hormigón. PhD Thesis, UPC, Barcelona (Spain).

Chiaia, B. Fantilli, A.P. Vallini, P. 2009a. Combining fiber-reinforced concrete with traditional reinforcement in tunnel linings. Engineering Structures 31 (7), 1600-1606.

Chiaia, B., Fantilli, A.P., Vallini, P., 2009b. Evaluation of minimum reinforcement ratio in FRC members and application to tunnel linings. RILEM Materials and Structures 42 (3), 339-351.

CNR DT 204/2006. 2006. Guidelines for the Design, Construction and Production Control of Fibre Reinforced Concrete Structures, Italian National Research Council - CNR.

CPH 2008. EHE-08: Instrucción del Hormigón Estructural.

Darby, A.W., MacDonald, M., 2003. The Airside Road Tunnel, Heathrow Airport, England. In: Proceedings of the Rapid Excavation \& Tunneling Conference RETC 2003, New Orleans (USA), 15-18 June, pp. 638647.

DBV - Recommendation (German Concrete Association). 1992. Design principles of steel fibre reinforced concrete for tunnelling works, pp. 19-29.

de la Fuente, A., Aguado, A., Molins, C., 2008. Numerical model for the nonlinear analysis of precast and sequentially constructed sections. Hormigón \& Acero 57 (247), 69-87. [In Spanish].

de la Fuente, A., Aguado, A., Molins, C., Armengou, J., 2010a. Innovations on components and testing for precast panels to be used in reinforced earth retaining walls. Construction and Building Materials. [In Press].

de la Fuente, A., de Figueiredo, A.D., Aguado, A., Molins, C., Chama Neto, P.J., 2010b. Experimentation and numerical simulation of steel fibre reinforced concrete pipes. Materiales de Construcción. [In press].

di Prisco, M., Toniolo, G., 2000. Structural applications of steel fibre reinforced concrete. In: Proceedings of International Workshop, Milan (Italy), April 4, 2000 (CTE Publ., Milan (Italy)).

di Prisco, M., Plizzari, G., Vandewalle, L., 2009. Fibre reinforced concrete: New design perspectives. RILEM Materials and Structures 42 (9), 1169-1171.

ENV 1992-1-1/2005. Eurocode 2: Design of concrete structures - Part 1-1: General rules and rules for buildings. CEN.

FIB MODEL CODE 2007 Fibre Reinforced Concrete, Draft version. Joint Paper by Falkner, H. (Germany), di Prisco, M., and Plizzari, G. (Italy).

Itasca Consulting Group Inc. 2006. FLAC-3D Manual: Fast Lagrangian Analysis of Continua in 3 Dimensions. Version 3.10. Itasca Consulting Group Inc., Minnesota (USA).

Jones, J., 2009. Steel and synthetic fiber in tunnels and mine, Technical Report. BASF 2009.

Kasper, T., Edvardsen, C., Wittneben, G., Neumann, D., 2008. Lining design for the district heating tunnel in Copenhagen with steel fibre reinforced concrete segments. Tunnelling and Underground Space Technology 23 (5), 574-587.

Levi, F., 1985. On minimum reinforcement in concrete structures. ASCE Journal Structural Engineering 111 (12), 2791-2796.

MACCAFERRI 2009. Hobson Bay Sewer Tunnel. Case History. Technical Report 1, October 2009. 
Molins, C., Marí, A.R., García, T., 2009. On-site stress tests of lining segments for Barcelona's underground tunnel. Scientific journal HBM measurement. Report in: Applied Measurement. ISSN 1614-9912.

Nguyen, D.T., 2006. TBM and lining - essential interfaces. Master Thesis. Politecnico di Torino (Italy).

Plizzari, G.A., Cominoli, L., 2005. Numerical simulations of SFRC precast tunnel segments. In: World Tunnel Congress ITA-AITES 2005, Istambul (Turkey), May 7-12, pp. 1105-1111.

Plizzari, G.A., Tiberti, G., 2006. Steel fibres as reinforcement for precast tunnel segments. Tunnelling and Underground Space Technology 21 (3-4) pp. 438-439. Special Issue: Safety in Underground Space (CD-ROM Proceedings of the ITA-AITES 2006 World Tunnel Congress and 32nd $I T A$ General Assembly).

RILEM TC 162-TDF, 2003. Test and design methods for steel fibre reinforced concrete. $\sigma-\varepsilon$ design method: Final recommendation. RILEM Materials and Structures 36 (262), 560-567.

Sandy, A., 2008. Clem Jones Tunnel joins up ahead of schedule. In: Queensland Newspapers (12-08-2008).

Telles, R.C.A., de Figueiredo, A.D., 2006. The possibility of using new technologies in precast concrete segments for TBM-excavated tunnels. Concreto e Construção 33 (41), 30-35. [In Portuguese].

Tiberti, G., Plizzari, G.A., Walraven, J., Blom, CBM. 2008. Concrete tunnel segments with combined traditional and fiber reinforcement. Tailor Made Concrete Structures, 2008, Chapter 37. Walraven \& Stoelhorst (eds.) 2008 Taylor \& Francis Group, London, ISBN 978-0-415-47535-8.

Tiberti, G., Plizzari, G.A., 2008. Final concrete linings with optimized reinforcement. In: World Tunnel Congress ITA-AITES 2008, Agra (India), September 22-24, pp. 922-932.

Vandewalle, L., 2000. Cracking behaviour of concrete beams reinforced with a combination of ordinary reinforcement and steel fibers. RILEM Materials and Structures 33 (3), 164-170.

Vandewalle, M., 2005. Tunnelling is an art. Ed. by N.V. BEKAERT, S.A., Zwevegem (Belgium). 400 pp.

Waal, R.G.A. de., 1999. Steel fibre reinforced tunnel segments for the application in shield driven tunnel linings. ISBN 90-407-1965-9, Delft (The Netherlands).

Walraven, J., 2009. High performance fibre reinforced concrete: progress in knowledge and design codes. RILEM Materials Structures 42 (9), 1247-1260.

Yang, W.Y., Wenwu, C., Chung, T.S., Morris, J., 2005. Applied numerical methods using Matlab. John Wiley \& Sons Inc., Hoboken, New Jersey (USA).

\section{Nomenclature}

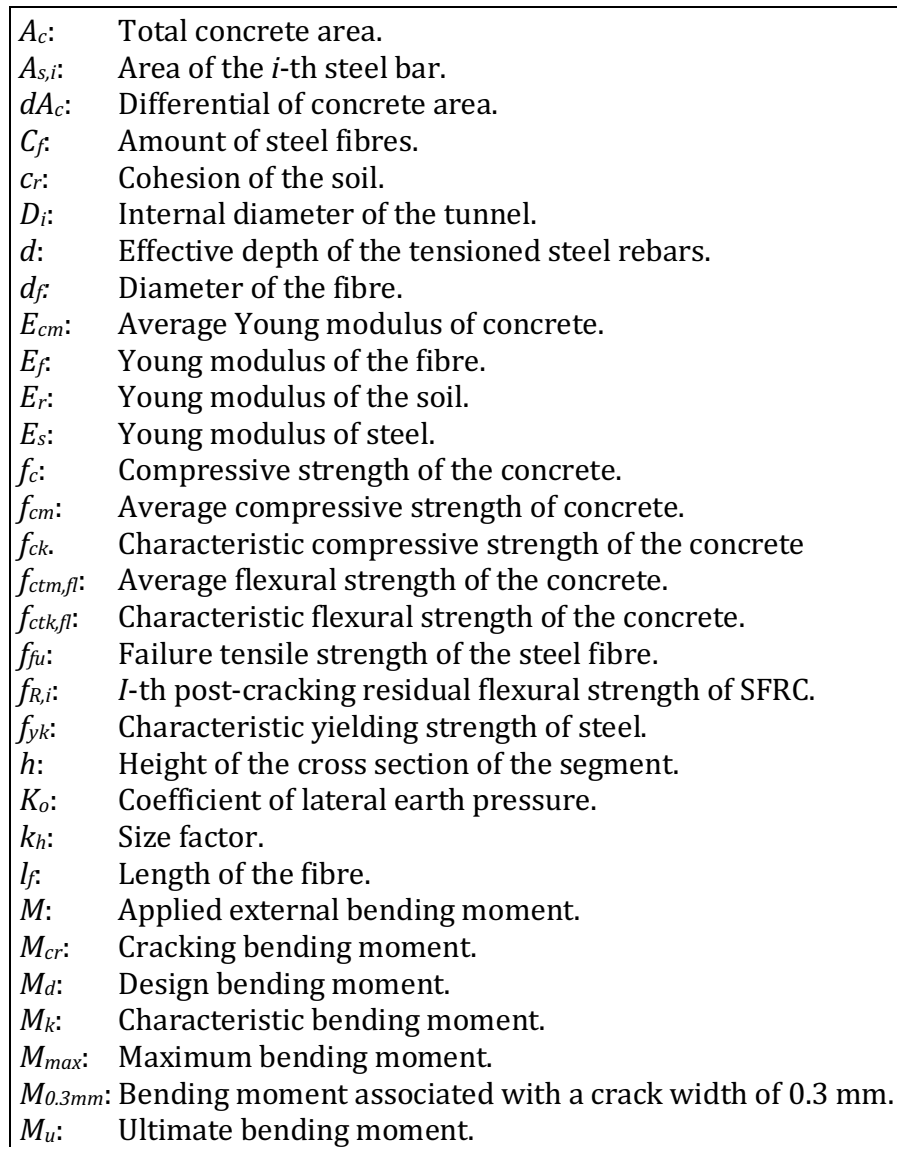




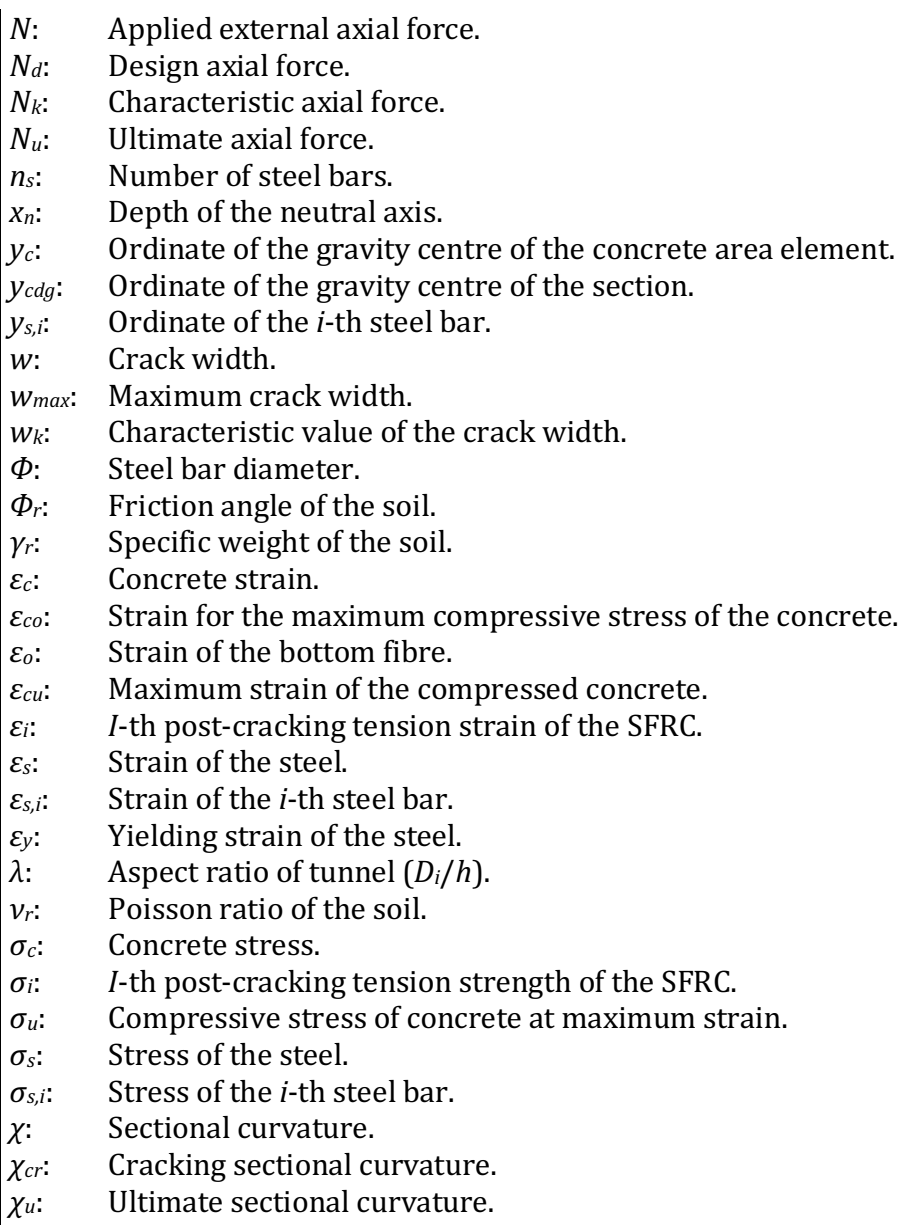

